\title{
Title: Dynamics of Brain Structure and its Genetic Architecture over the Lifespan
}

Rachel M. Brouwer ${ }^{1}$, Marieke Klein ${ }^{1-4}$, Katrina L. Grasby ${ }^{5}$, Hugo G. Schnack ${ }^{1}$, Neda Jahanshad $^{6}$, Jalmar Teeuw ${ }^{1}$, Sophia I. Thomopoulos ${ }^{6}$, Emma Sprooten 7 , Carol E. Franz ${ }^{8}$, Nitin Gogtay ${ }^{9}$, William S. Kremen, 10 , Matthew S. Panizzon', Loes M. Olde Loohuis'11, Christopher D. Whelan'2, Moji Aghajani13, Clara Alloza ${ }^{14}$, Dag Alnæs ${ }^{15,16}$, Eric Artiges ${ }^{17}$, Rosa Ayesa-Arriola ${ }^{18}$, Gareth J. Barker ${ }^{19}$, Elisabet Blok ${ }^{20}$, Erlend Bøen ${ }^{21}$, Isabella A. Breukelaar22, Joanna K. Bright 6 , Elizabeth E. L. Buimer ${ }^{1}$, Robin Bülow23, Dara M. Cannon ${ }^{24}$, Simone Ciufolini25, Nicolas A. Crossley25,26, Christienne G. Damatac7, Paola Dazzan²7, Casper L. de $\mathrm{Mol}^{28}$, Sonja M. C. de Zwarte ${ }^{1}$, Sylvane Desrivières ${ }^{29}$, Covadonga M. Díaz-Caneja ${ }^{14}$, Nhat Trung Doan ${ }^{15}$, Katharina Dohm ${ }^{30}$, Juliane H. Fröhner ${ }^{31}$, Janik Goltermann ${ }^{30}$, Antoine Grigis ${ }^{32}$, Dominik Grotegerd ${ }^{30}$, Laura K. M. Han ${ }^{13}$, Catharina A. Hartman ${ }^{33}$, Sarah J. Heany ${ }^{34}$, Walter Heindel ${ }^{35}$, Dirk J. Heslenfeld ${ }^{36}$, Sarah Hohmann ${ }^{37}$, Bernd Ittermann ${ }^{38}$, Philip R. Jansen ${ }^{20,39}$, Joost Janssen ${ }^{14}$, Tianye Jia ${ }^{40,41}$, Jiyang Jiang ${ }^{42}$, Christiane Jockwitz ${ }^{43,44}$, Temmuz Karali45,46, Daniel Keeser ${ }^{45-47}$, Martijn G. J. C. Koevoets ${ }^{1}$, Rhoshel K. Lenroot ${ }^{48-50}$, Berend Malchow ${ }^{51}$, René C. W. Mandl1 1 , Vicente Medel26, Susanne Meinert ${ }^{30}$, Catherine A. Morgan ${ }^{52,53}$, Thomas W. Mühleisen 43,54,55, Leila Nabulsi24, Nils Opel30, Víctor Ortiz-García de la Foz ${ }^{56}$, Bronwyn J. Overs $^{50}$, Marie-Laure Paillère Martinot 17,57 , Erin B. Quinlan ${ }^{41}$, Ronny Redlich ${ }^{58}$, Tiago Reis Marques ${ }^{25,59}$, Jonathan Repple ${ }^{30}$, Gloria Roberts ${ }^{48}$, Gennady V. Roshchupkin ${ }^{60,61}$, Nikita Setiaman $^{1,20}$, Elena Shumskaya ${ }^{3,7}$, Frederike Stein ${ }^{62}$, Gustavo Sudre ${ }^{63}$, Shun Takahashi45,64, Anbupalam Thalamuthu42, Diana Tordesillas-Gutiérrez 56,65 , Aad van der Lugt61, Neeltje E. M. van Haren ${ }^{1,20}$, Wei Wen ${ }^{42}$, Henk-Jan Westeneng ${ }^{66}$, Katharina Wittfeld ${ }^{67,68}$, Andre Zugmann, Nicola J. Armstrong70, Janita Bralten ${ }^{3}$, Shareefa Dalvie ${ }^{34}$, Marta Di Forti29, Linda Ding ${ }^{6}$, Gary Donohoe $^{71}$, Andreas J. Forstner ${ }^{72,73}$, Javier Gonzalez-Peñas ${ }^{14}$, Joao P. O. F. T. Guimaraes ${ }^{3,7}$, Georg Homuth $^{74}$, Jouke-Jan Hottenga ${ }^{75}$, Maria J. Knol ${ }^{60}$, John B. J. Kwok ${ }^{76,77}$, Stephanie Le Hellard78,79, Karen A. Mather 42,50 , Yuri Milaneschi 13, Derek W. Morris' ${ }^{71}$, Markus M. Nöthen73, Sergi Papiol45,65,80, Marcella Rietschel81, Marcos L. Santoro69,82, Vidar M. Steen ${ }^{78,79}$, Jason L. Stein ${ }^{83}$, Fabian Streit81, Rick M. Tankard70, Alexander Teumer ${ }^{84}$, Dennis van 't Ent ${ }^{75}$, Dennis van der Meer 15,16,85, Kristel R. van Eijk66, Evangelos Vassos ${ }^{29,86}$, Javier Vázquez-Bourgon 65,87 , Stephanie H. Witt81, Alzheimer's Disease Neuroimaging Initiative ${ }^{*}$, Hieab H. H. Adams ${ }^{61,88}$, Ingrid Agartz ${ }^{15,89,90}$, David Ames ${ }^{91,92}$, Katrin Amunts ${ }^{43,54}$, Ole A. Andreassen ${ }^{15,16}$, Celso Arango ${ }^{14}$, Tobias Banaschewski37, Bernhard T. Baune ${ }^{30,93,94}$, Sintia I. Belangero69,82, Arun L. W. Bokde95, Dorret I. Boomsma ${ }^{96}$, Rodrigo A. Bressan69,97, Henry Brodaty42, Jan K. Buitelaar 7,98 , Wiepke Cahn 1,99 , Svenja Caspers ${ }^{43,100}$, Sven Cichon ${ }^{43,55,101}$, Benedicto Crespo Facorro65,102, Udo Dannlowski ${ }^{30}$, Torbjørn Elvsåshagen 103-105, Thomas Espeseth 106,107, Peter G. Falkai45, Simon E. Fisher 4,108 , Herta Flor 109 , Janice M. Fullerton 50,77 , Hugh Garavan ${ }^{110}$, Penny A. Gowland ${ }^{111}$, Hans J. Grabe ${ }^{67,68}$, Tim Hahn ${ }^{30}$, Andreas Heinz ${ }^{112}$, Manon Hillegers ${ }^{1,20}$, Jacqueline Hoare ${ }^{34}$, Pieter J. Hoekstra'113, Mohammad A. Ikram60, Andrea P. Jackowski ${ }^{69}$, Andreas Jansen62,114, Erik G. Jönsson 15,89, Rene S. Kahn'15,116, Tilo Kircher62, Mayuresh S. Korgaonkar22,76, Axel Krug 62,117 , Herve Lemaitre ${ }^{118}$, Ulrik F. Malt 119, Jean-Luc Martinot ${ }^{17}$, Colm McDonald24, Philip B. Mitchell48,120, Ryan L. Muetzel20, Robin M. Murray26, Frauke Nees ${ }^{109,121,}$ Igor Nenadic62, Jaap Oosterlaan ${ }^{122}$, Roel A. Ophoff11,123, Pedro M. Pan69,124, Brenda W. J. H. Penninx ${ }^{13}$, Luise Poustka ${ }^{125}$, Perminder S. Sachdev42,126, Giovanni A. Salum ${ }^{127,128}$, Peter R. Schofield50,77, Gunter Schumann41,129,130, Philip Shaw63,131, Kang Sim ${ }^{132,133}$, Michael N. Smolka ${ }^{134}$, Dan J. Stein ${ }^{135}$, Julian Trollor ${ }^{42,136}$, Leonard H. van den Berg66, Jan H. Veldink66, Henrik Walter ${ }^{137}$, Lars T. Westlye $\mathrm{e}^{15,16,106}$, Robert Whelan 138 , Tonya White ${ }^{20,61}$, Margaret J. Wright ${ }^{139,140}$, Sarah E. Medland ${ }^{141}$, Barbara Franke ${ }^{3,4,142}$, Paul M. Thompson', Hilleke E. Hulshoff Pol 1

\section{AFFILIATIONS AT THE END OF THE MANUSCRIPT}

AUTHOR LIST INFORMATION: We have made every effort to ensure that the author list includes all appropriate persons who fulfill criteria to be named authors, but if this appears to 
be in error, or if you have been omitted, please contact Rachel Brouwer or Hilleke Hulshoff Pol and we will endeavor to fix it promptly.

\section{One-sentence summary}

We identified common genetic variants associated with the rate of brain development and aging, in longitudinal MRI scans worldwide.

\section{Abstract}

Human brain structure changes throughout our lives. Altered brain growth or rates of decline are implicated in a vast range of psychiatric, developmental, and neurodegenerative diseases. While heritable, specific loci in the genome that influence these rates are largely unknown. Here, we sought to find common genetic variants that affect rates of brain growth or atrophy, in the first genome-wide association analysis of longitudinal changes in brain morphology across the lifespan. Longitudinal magnetic resonance imaging data from 10,163 individuals aged 4 to 99 years, on average 3.5 years apart, were used to compute rates of morphological change for 15 brain structures. We discovered 5 genome-wide significant loci and 15 genes associated with brain structural changes. Most individual variants exerted age-dependent effects. All identified genes are expressed in fetal and adult brain tissue, and some exhibit developmentally regulated expression across the lifespan. We demonstrate genetic overlap with depression, schizophrenia, cognitive functioning, height, body mass index and smoking. Several of the discovered loci are implicated in early brain development and point to involvement of metabolic processes. Gene-set findings also implicate immune processes in the rates of brain changes. Taken together, in the world's largest longitudinal imaging genetics dataset we identified genetic variants that alter agedependent brain growth and atrophy throughout our lives.

\section{Introduction}

Under the influence of genes and a varying environment, human brain structure changes throughout the lifespan. Even in adulthood, when the brain seems relatively stable, individuals differ in the profile and rate of brain changes (Hedman et al., 2012). Longitudinal studies are crucial to identify genetic and environmental factors that influence the rate of these brain changes throughout development (Giedd et al., 1999; Gogtay et al., 2004; Shaw, Gogtay, \& Rapoport, 2010) and aging (Raz et al., 2005). Interindividual differences in brain development are associated with general cognitive function (Ramsden et al., 2011; Schnack et al., 2015; Oschwald et al., 2019), and risk for psychiatric disorders (Shaw et al., 2009; Liberg et al., 2016) and neurological diseases (Reiter et al., 2017; Eshaghi et al., 2018; Jiskoot et al., 2019). Genetic factors involved in brain development and aging overlap with those for cognition (Brans et al., 2010; Brouwer et al., 2014) and risk for neuropsychiatric disorders (Brans et al., 2008). A recent crosssectional study showed a genetic component to advanced brain age in 
several brain disorders (Kaufmann et al., 2019). Yet, we still lack information on which genetic variants influence individual brain changes throughout life, since this requires longitudinal data. Discovering genetic factors for brain changes may reveal key biological pathways that drive normal development and ageing, and may contribute to identifying disease risk and resilience: a crucial goal given the urgent need for new treatments for aberrant brain development and aging worldwide.

As part of the Enhancing Imaging Genetics through Meta-Analysis (ENIGMA) consortium (Thompson et al., 2014; 2020), the ENIGMA Plasticity Working Group recently quantified the overall genetic contribution to longitudinal brain changes by combining evidence from multiple twin cohorts across the world (Brouwer et al., 2017). Most global and subcortical brain measures showed genetic influences on change over time, with a higher genetic contribution in the elderly (heritability $16-42 \%$ ). Genetic factors that influence longitudinal changes were partially independent of those that influence baseline volumes of brain structures, suggesting that there might be genetic variants that specifically affect the rate of development or aging. Even so, the genes involved in these processes are still not known. So far, only a single, small-scale genome-wide association study (GWAS) was performed for brain change (Szekely et al., 2018; $N=715$ ). Here, we set out to find genetic variants that may influence rates of brain changes over time, using genome-wide analysis in individuals scanned with magnetic resonance imaging (MRI) on more than one occasion. We also aimed to identify agedependent effects of genomic variation on longitudinal brain changes in mostly healthy, but also neurological and psychiatric, populations.

In our GWAS meta-analysis, we sought genetic loci associated with annual change rates in 8 global and 7 subcortical morphological brain measures. We performed a coordinated analysis of 37 longitudinal cohorts ( $N$ $=10,163$, with a 3.5-year interval between scans on average, $22 \%$ of participants with a neurological or psychiatric diagnosis, $50 \%$ females, mainly of European descent (95\%), aged 4 to 99 years (Supplementary Figure S1, Supplementary Tables S1-S3). Global and subcortical brain measures were extracted, and annual change rates were analyzed using additive genetic association analyses to estimate effects of genetic variants on rates of change within each cohort. As brain change is not constant over age (Hedman et al., 2012), and gene expression also changes during development and aging (Kang et al., 2011), we determined whether the estimated genetic variants were age-dependent, i.e., differentially affected rates of brain changes at different stages of life using genome-wide meta-regression models with linear or quadratic age effects (Materials and Methods).

\section{Results}

\section{Longitudinal trajectories}

Change in global brain measures showed different trajectories of change with age (Figure 1 and Supplementary Video), characterized by either monotonic increases (lateral ventricles), monotonic decreases (cortex volume, cerebellar 
gray matter volume, cortical thickness, surface area, total brain volume), or increases followed by stabilization and subsequently decreases (cerebral and cerebellar white matter, thalamus, caudate, putamen, nucleus accumbens, pallidum, hippocampus and amygdala). Each brain structure showed a characteristic trajectory of change, as reflected by generally low correlation coefficients between rates of change (Supplementary Figure S2). Using the correlation structure, we estimated the effective number of independent variables through matrix spectral decomposition on the rates of change (Nyholt, 2004), yielding 14 independent traits for multiple testing corrections (Materials and Methods).

\section{Age-independent associations with brain-structural change rates}

Two loci showed genome-wide significant effects on the rate of brain change in cohorts of European ancestry (Table 1; Supplementary Figure S3 provides Manhattan plots, QQ plots, and locus plots; Supplementary Figure S4). The first lead SNP, rs72772740 on chromosome 16, is an intronic variant located in the GPR139 gene and was associated with change in lateral ventricle volume (Figure 2). Functional annotation identified numerous significant eQTL associations (FDR <0.05) in different datasets and highlighted genes by either eQTL mapping (GPRC5B, IQCK, KNOP1, C16orf62) or chromatin interaction mapping ( $A C S M 1, A C S M 5, U M O D, G P 2)$. GPR139 is the Gprotein-coupling receptor gene 139 , which encodes a member of the rhodopsin family of G-protein coupled receptors. The gene is almost exclusively expressed in the central nervous system, with highest expression from 12 to 26 weeks post-conception, and has been suggested as a therapeutic target for metabolic syndromes and motor diseases (Nohr 2019). GPR139 may play a role in fetal brain development (Süsens et al., 2006). The second lead SNP, rs449998, an intronic variant on chromosome 21 located in the Down Syndrome Cell Adhesion Molecule (DSCAM) gene, was associated with change in nucleus accumbens volume. Chromatin interactions highlighted DSCAM and additional genes as likely effector transcripts at this locus. DSCAM encodes a member of the immunoglobulin superfamily of cell adhesion molecules (Ig-CAMs), and is involved in the development of the human central and peripheral nervous system (Yamakawa et al., 1998). This gene has been identified in the critical Down syndrome region and is also a candidate risk gene for congenital heart disease (Agarwala et al., 2000).

\section{Age-dependent associations with brain-structural change rates}

The association of three additional loci with rate of change was variable across the lifespan (Table 1; Supplementary Figure S3 provides Manhattan plots, QQ plots, and locus plots; Supplementary Figure S4): white matter cerebellum volume change was affected by the intronic rs10674957 in the Thyrotropin Releasing Hormone Degrading Enzyme (TRHDE) gene, white matter cerebrum volume change was affected by rs573983368 (intronic variant) in the Dachshund Family Transcription Factor $1(D A C H 1)$ gene, and rs6864758 (intergenic and located in long intergenic non-protein coding RNA 
Table 1: SNPs for age-(in)dependent effect on longitudinal brain changes.

\begin{tabular}{|c|c|c|c|c|c|c|c|c|c|c|}
\hline $\begin{array}{l}\text { Phenotype } \\
\text { (change rate) }\end{array}$ & SNP id & Chr & Position $^{a}$ & \begin{tabular}{|l|} 
Tested \\
Allele \\
/Non- \\
tested \\
Allele
\end{tabular} & $\begin{array}{l}\text { Frequency } \\
\text { Tested } \\
\text { Allele }\end{array}$ & $\begin{array}{l}\text { Age- } \\
\text { dependency } \\
\text { model }\end{array}$ & $\begin{array}{l}\text { Effect on } \\
\text { change rate: } \\
\text { Estimated model }\end{array}$ & P-value & $\begin{array}{l}\text { Gene in } \\
\text { locus }\end{array}$ & Description of effect of tested allelec: \\
\hline Surface Area* & rs6864758 & 5 & 157750349 & $a / g$ & 0.6341 & linear & $\begin{array}{l}-95.91+2.181 \mathrm{x} \\
\text { age in } \mathrm{mm}^{2} / \text { year }\end{array}$ & $1.96 e-08$ & \begin{tabular}{|l|} 
intergenic; \\
located in \\
long \\
intergenic \\
non-protein \\
coding RNA \\
(LINC02227)
\end{tabular} & $\begin{array}{l}\text { less growth in children, less decline in } \\
\text { older age }\end{array}$ \\
\hline $\begin{array}{l}\text { Cerebellum } \\
\text { White Matter }\end{array}$ & rs10674957 & 12 & 72717608 & g/gagat & 0.3051 & linear & $\begin{array}{l}-47.49+1.242 \mathrm{x} \\
\text { age in } \mathrm{mm}^{3} / \text { year }\end{array}$ & $1.30 \mathrm{e}-08$ & $\begin{array}{l}\text { intron } \\
\text { variant, } \\
\text { TRHDE }\end{array}$ & $\begin{array}{l}\text { less growth in children, less decline in } \\
\text { older age }\end{array}$ \\
\hline $\begin{array}{l}\text { Cerebral } \\
\text { White Matter }\end{array}$ & rs573983368 & 13 & 72353395 & $a / g$ & 0.3113 & quadratic & \begin{tabular}{|l|}
$899.15-56.726$ \\
$x$ age $+0.683 x$ \\
age $^{2}$ in $m^{3} /$ year
\end{tabular} & $1.41 \mathrm{e}-09$ & $\begin{array}{l}\text { intron } \\
\text { variant, } \\
\mathrm{DACH} 1\end{array}$ & $\begin{array}{l}\text { more growth in children, less decline in } \\
\text { older age }\end{array}$ \\
\hline $\begin{array}{l}\text { Lateral } \\
\text { Ventricles }\end{array}$ & rs72772740 & 16 & 20064855 & $t / g$ & 0.8841 & constant & $\begin{array}{l}63.255 \text { in } \\
\mathrm{mm}^{3} / \text { year }\end{array}$ & $1.06 \mathrm{e}-08$ & $\begin{array}{l}\text { intron } \\
\text { variant, } \\
\text { GPR139 }\end{array}$ & more growth over the whole lifespan \\
\hline $\begin{array}{l}\text { Nucleus } \\
\text { Accumbens }\end{array}$ & rs449998 & 21 & 41467826 & $a / g$ & 0.2423 & constant & $\begin{array}{l}-1.954 \text { in } \\
\mathrm{mm}^{3} / \text { year }\end{array}$ & $4.65 e-08$ & $\begin{array}{l}\text { intron } \\
\text { variant, } \\
\text { DSCAM }\end{array}$ & $\begin{array}{l}\text { less growth in children, less decline in } \\
\text { adults }\end{array}$ \\
\hline
\end{tabular}

a Position based on build hg19. Data was clumped $(p<1 \mathrm{e}-04)$ to identify significant and LD-independent SNPs. bP-values are obtained by testing the age-independent effect versus no effect at all (age-dependency is "none") or age-related effects versus main effect only (age-dependency is linear 1 degree of freedom - or quadratic - two degrees of freedom). ${ }^{*}$ This locus also showed a genome-wide significant quadratic age effect. The most parsimonious model is listed in this table. Single significant SNPs without strong LD neighbors were omitted from this table. cSee Figure 1,

Supplementary Figures S4 for the lifespan trajectories and a visualization of the effect of this locus. 
LINC02227) on chromosome 5 had an age-dependent effect on the change in surface area (Figure 2; Table 1). Both the TRHDE and DACH1 loci show significant chromatin interaction. TRHDE encodes a member of the peptidase M1 family. The encoded protein is an extracellular peptidase that specifically cleaves and inactivates the neuropeptide thyrotropin-releasing hormone (Bauer et al., 1999). Concurring with this, knockdown of TRHDE in Drosophila sensory neurons is known to result in altered cellular morphology, impaired nociception and the sensory response to (potentially) harmful stimuli (Nagy et al., 2015). In our study, carriers of the minor allele showed a slower increase of cerebellum white matter, followed by reduced decline in older age (Supplementary Figure S5). DACH1 encodes a chromatin-associated protein that associates with DNA-binding transcription factors to regulate gene expression and cell fate determination during development. $D A C H 1$ is highly expressed in the proliferating neuroprogenitor cells of the developing cortical ventricular and subventricular regions, and in the striatum (Castiglioni et al., 2019). We found the effect of $D A C H 1$ to have a quadratic age-dependence, with the variant being associated with faster growth in childhood and earlier but slower decline with aging (Figure 2). To visualize the age-dependent effects, we plotted the meta-regression results for the significant loci (Materials and Methods, Supplementary Figure S5). The top-10 loci for each phenotype and age model are presented in Supplementary Tables S4 to S6.

\section{Gene-based analyses}

Gene-based associations with all phenotypes were estimated using MAGMA (version 1.07b; de Leeuw et al., 2015) based on summary statistics from our GWAS meta-analyses and meta-regressions. Gene names and locations were derived based on ENSG v92 (Zerbino et al., 2018). We found 15 genome-wide significant genes influencing structural rates of change (Table 2); among these, two genes reached study-wide significance, GPR139 and TMCO2. GPR139 was again associated with change in lateral ventricle volume in this analysis, and the Trans-Membrane and Coiled-coil domains 2 gene, TMCO2, was associated with an age-dependent change in thalamic volume. DACH1 and GPR39, which were implicated through SNP-based GWAS, also reached genome-wide significance in this gene-based GWAS. Additional genome-wide significant findings included age-related effects of the Alzheimer's disease (AD)-related Apolipoprotein E gene (APOE) on change rates for both hippocampus and amygdala (Figure 2). Of note, this finding was based on GWAS and subsequent gene analysis, and we did not investigate the classical $A P O E$ status, since that is determined by a combination of two SNPs. However, we found that the effect of $A P O E$ on both phenotypes was fully driven by rs429358, with the risk variant for AD causing faster increases in childhood for amygdala and faster decay for both amygdala and hippocampus later in life (Figure 2). To visualize the age-dependent effects, we plotted the meta-regression results for the top SNP in each of the significant genes (Supplementary Figure S5). Supplementary Table S7 details putative biological functions of associated genes and genes harboring 
Table 2: Genes contributing to longitudinal brain changes.

\begin{tabular}{|c|c|c|c|c|c|c|c|c|}
\hline Phenotype (change rate) & Gene & Chr & Start positiona & $\begin{array}{l}\text { Stop } \\
\text { positiona }\end{array}$ & $\begin{array}{l}\# \\
\text { independent } \\
\text { SNPs } \\
\end{array}$ & Age dependency & $\mathrm{Z}$ & P-value \\
\hline Thalamus* & TMCO2 & 1 & 40711619 & 40717363 & 3 & linear & 5.410 & $3.14 \mathrm{e}-08$ \\
\hline Cerebellum Gray Matter & EPAS1 & 2 & 46520806 & 46613836 & 18 & constant & 4.590 & $2.22 \mathrm{e}-06$ \\
\hline Cerebellum Gray Matter & PID1 & 2 & 229715242 & 230136001 & 79 & quadratic & 4.697 & $1.32 \mathrm{e}-06$ \\
\hline Cortical Thickness & $A C 027309.1$ & 5 & 172036245 & 1720364361 & 1 & linear & 4.572 & $2.42 \mathrm{e}-06$ \\
\hline Putamen & TMEMЗОA & 6 & 75962640 & 75994684 & 3 & constant & 4.911 & $4.53 e-07$ \\
\hline Total Brain & STEAP1B & 7 & 22459063 & 22672544 & 39 & quadratic & 4.815 & $7.36 \mathrm{e}-07$ \\
\hline Cerebellum Gray Matter & $T M C 1$ & 9 & 75136717 & 75451267 & 20 & quadratic & 4.708 & $1.25 \mathrm{e}-06$ \\
\hline Cerebral White Matter & $D A C H 1$ & 13 & 72012098 & 72441330 & 21 & quadratic & 4.984 & $3.11 \mathrm{e}-07$ \\
\hline Lateral Ventricles & GPR139 & 16 & 20042807 & 20085239 & 16 & constant & 5.724 & $5.20 \mathrm{e}-09$ \\
\hline Cortex & $A B R$ & 17 & 906758 & 1132315 & 53 & quadratic & 4.626 & $1.86 \mathrm{e}-06$ \\
\hline Cerebral White Matter & $M Y O C D-A S 1$ & 17 & 12626199 & 12661542 & 10 & linear & 4.709 & $1.24 \mathrm{e}-06$ \\
\hline Caudate & PLCD3 & 17 & 43186335 & 43210721 & 13 & linear & 4.692 & $1.35 \mathrm{e}-06$ \\
\hline Cerebellum White Matter & OR7D2 & 19 & 9296279 & 9299493 & 2 & linear & 4.637 & $1.77 \mathrm{e}-06$ \\
\hline Amygdala & $A P O E$ & 19 & 45409011 & 45412650 & 2 & linear & 4.607 & $2.05 \mathrm{e}-06$ \\
\hline Hippocampus & $A P O E$ & 19 & 45409011 & 45412650 & 2 & quadratic & 4.889 & $5.07 e-07$ \\
\hline
\end{tabular}

a Position based on build hg19. Study-wide significant hits are displayed in bold. *This gene also showed a genome-wide significant quadratic age effect. The most parsimonious model is listed in this table. 
genome-wide significant associated loci. Supplementary Table S8 displays the top-10 genes for each phenotype and each age model.

\section{Gene-set analyses}

To test whether genetic findings for brain structure change converged onto functional gene sets and pathways, we conducted gene-set analyses using MAGMA (see Methods). We tested the associations of 9,975 gene sets derived from the MSigDB 7.0 (Subramanian et al., 2005) using gene-based $p$ values. Competitive testing was used and revealed five genome-wide significant gene sets (Table 3, see Supplementary Table S9 for top-10 gene sets and genes included). Two of these reached study-wide significance: the interleukin-1 (IL-1) receptor activity gene set for age-dependent genetic associations with cortical volume change and the response to interleukin-2 (IL-2) gene set for age-independent genetic associations with thalamic change. There were no overlapping genes in these gene sets. These gene sets are immune system-related, and both IL-1 and IL-2 are known to affect the growth and survival of neural cells (Hanisch and Quirion, 1996; Borsini et al., 2015). The finding of immune-related gene sets in both these structures is intriguing given the extensive reciprocal structural connections of thalamus with the cerebral cortex (Zhang et al., 2010; Bolkan et al., 2017) and the known phenotypic and genetic link between psychiatric and immune-related disorders (Lambert et al., 2013, Psychiatric Genomics Consortium, 2014; Wang et al., 2015; Jeppesen et al., 2019; Pouget et al., 2019).

\section{Post-hoc analyses}

\section{Overlap with cross-sectional findings}

SNP-based heritability estimates $\left(h^{2}\right)$ of the rates of change based on linkage disequilibrium score regression (LDSC; Bulik-Sullivan et al., 2015) were small overall (Supplementary Table S10). For all phenotypes, the $\mathrm{h}^{2} \mathrm{z}$-score was below 4 , so we tested for genetic overlap with cross-sectional brain data and other phenotypes by applying approaches other than LDSC: to investigate whether cross-sectional GWAS for brain structure and our GWAS on rates of change identify the same or different genetic variants, we investigated overlap between rate of change and earlier published data on cross-sectional brain structure of the same structure (where available, Materials and Methods). Supplementary Figure S6 displays the number of overlapping genes tested against the expected number of overlapping genes that would occur by chance, in the first 1-1,000 ranked genes. Supplementary Table S8 lists the top-10 gene findings for each of the 15 change rate phenotypes and compares these with the gene ranks from cross-sectional data. In the top-10 ranked genes, no overlap was seen for 11 of the measured phenotypes, and only up to 2 overlapping genes were observed for the remaining 4 phenotypes. These genes included $A P O E$, a major genetic risk factor for $A D$ (Wolfe et al., 2019), which influenced change in both amygdala and hippocampus differentially across the lifespan. Additional top genes for 
Table 3: Gene-sets for age-(in)dependent effect on longitudinal brain changes.

\begin{tabular}{|l|l|l|l|l|l|}
\hline $\begin{array}{l}\text { Phenotype } \\
\text { (change } \\
\text { rate) }\end{array}$ & $\begin{array}{l}\text { Age- } \\
\text { dependency }\end{array}$ & GO-term & $\begin{array}{l}\# \\
\text { genes }^{a}\end{array}$ & P-value & Brief description \\
\hline Cortex & linear & GO_SECRETORY_GRANULE_LOCALIZATION & 11 & $6.39 e-07$ & $\begin{array}{l}\text { Any process in which a secretory granule is transported to, and/or } \\
\text { maintained in, a specific location within the cell) }\end{array}$ \\
\hline Cortex & linear & GO_INTERLEUKIN_1_RECEPTOR_ACTIVITY & 6 & $\mathbf{6 . 8 0 e - 0 8}$ & $\begin{array}{l}\text { Combining with interleukin-1 to initiate a change in cell activity. } \\
\text { Interleukin-1 is produced mainly by activated macrophages and is } \\
\text { involved in the inflammatory response }\end{array}$ \\
\hline Pallidum & constant & GO_FLAVONOID_GLUCURONIDATION & 9 & 1.51 -06 & $\begin{array}{l}\text { The modification of a flavonoid by the conjugation of glucuronic } \\
\text { acid. The resultant flavonoid glucuronosides are often much more } \\
\text { water-soluble than the precursor. }\end{array}$ \\
\hline Thalamus & constant & GO_RESPONSE_TO_INTERLEUKIN_2 & 12 & $\mathbf{1 . 1 2 e - 0 7}$ & $\begin{array}{l}\text { Any process that results in a change in state or activity of a cell or } \\
\text { an organism (in terms of movement, secretion, enzyme production, } \\
\text { gene expression, etc.) as a result of an interleukin-2 stimulus. }\end{array}$ \\
\hline Thalamus & linear & GO_GTPASE_REGULATOR_ACTIVITY & 259 & $2.63 e-06$ & $\begin{array}{l}\text { Modulates the rate of GTP hydrolysis by a GTPase. } \\
\end{array}$ \\
& & & &
\end{tabular}

Genome-wide significant gene sets based on gene ontology. Study-wide significant gene sets are displayed in bold. aSee Supplementary Table S9 for genes included in the gene set. Genes included in GO_INTERLEUKIN_1_RECEPTOR_ACTIVITY and GO_RESPONSE_TO_INTERLEUKIN_2 do not overlap. 
volume change that had previously been identified in GWAS of crosssectional volumes of the same structures were KTN1 (kinectin 1 gene) for putamen (Hibar et al., 2015), C16orf95 for ventricle volume (Elliot et al., 2018), and APOC1 (Apolipoprotein C-1) for amygdala and hippocampus (Hibar 2017, Satizabal 2019). Extending this search to the top 200 ( 1\% of genes), we found no other overlapping genes above chance level. In the top 1,000 ranked genes ( $5 \%$ of genes), overlapping genes did emerge (Supplementary Figure S6).

To test for global genomic overlap between our findings and GWAS of cross-sectional volumes we applied independent SNP-Effect Concordance Analyses (iSECA) (Nyholt, 2014; Materials and Methods) and tested for pleiotropy. We found no significant pleiotropy between longitudinal and crosssectional results, confirming a largely different genetic background for changes in brain structure and brain structure per se (Figure 3).

\section{Overlap with other traits}

We applied iSECA for overlap between our age-independent summary statistics for structural brain changes and several neuropsychiatric, neurological, physical, aging and disease-related phenotypes and psychological traits (Materials and Methods). We found significant genomic overlap $(p<1.6 \mathrm{e}-04)$ with genetic variants associated with depression (Howard et al., 2019), schizophrenia (Psychiatric Genomics Consortium, 2014), cognitive functioning (Savage et al., 2018), height (Yengo et al., 2018), body mass index (BMI; Yengo et al., 2018), and ever smoking (Watanabe et al., 2019). Despite significant pleiotropy between rates of change and these traits, the directions of effects varied across loci. (Figure 3, Supplementary Figure S7).

Of note, there was little overlap in the genetic loci associated with the longitudinal brain measures and intracranial volume at baseline, indicating that overall head size did not drive our findings (Figure 3).

\section{Gene expression in the brain across the lifespan}

We determined mRNA expression for genome-wide significant genes and genes associated with genome-wide significant SNPs (Tables 1 and 2) in 54 tissue types and in both the developing and adult human brain, through GENE2FUNC (Watanabe et al., 2017). For the prioritized genes, a gene expression heatmap was created, based on GTEx v8 RNAseq data (GTEx Consortium, 2015). This revealed considerable expression levels across several brain tissues for the following genes: $A B R, T M E M 30 A, A P O E$, EPAS1, PLCD3, and DSCAM, the latter showing higher relative expression in brain tissue compared to all other tissue types (Supplementary Figure S8A). TMCO2 was predominantly expressed in the testis. Expression heatmaps based on BrainSpan data (Miller et al., 2014) revealed that $D A C H 1$ shows highest relative expression during early prenatal stages (8-9 post conception weeks), compared to postnatal stages. A second cluster of genes demonstrated stable high relative expression levels throughout development 
and across the lifespan (APOE, ABR, TMEM30A, PID1). Two additional genes, EPAS1 and PLCD3, showed lower relative expression in the early prenatal stages and higher expression later in life (Supplementary Figure 8B).

\section{Phenome-wide associations}

For the prioritized SNPs and genes (Table 1 and 2), exploratory pheWAS (i.e., "phenome-wide") analysis was performed to systematically analyze many phenotypes for association with the genotype and individual genes (Supplementary Table S11). PheWAS was performed using publically available data from the GWASAtlas (https://atlas.ctglab.nl; Watanabe et al., 2019). Both a single variant (rs72772740) and gene associations of DACH1, GPR139 showed pleiotropic effects mainly in the metabolic domain, e.g., with estimated glomerular filtration rate and BMI (Supplementary Table S11, Supplementary Figure S9). APOE showed strong associations with cholesterol and lipids. Similarly, TMCO2 and PLCD3 showed significant associations with BMI-related phenotypes (Supplementary Table S11, Supplementary Figure S9).

\section{Sensitivity analyses}

We repeated the main analyses in various subgroups: 1) by adding four cohorts of non-European or mixed ancestry $(\mathrm{N}=540), 2)$ by omitting cohorts that did not meet a minimum sample size criterion $(\mathrm{N}>75)$ or a minimum scanning interval ( $>0.5$ years) leaving $N=9,105,3$ ) by excluding diagnostic groups in each cohort leaving $\mathrm{N}=7,309$, and 4) by including a covariate adjusting for disease status (Supplementary Tables S12-S14). In SNP-based analyses, effects sizes of SNPs were very similar in all subgroups, suggesting that our results are also applicable for individuals of non-European ancestry, the smaller cohorts, and in individuals irrespective of disease (Supplementary Table S12). For the gene-based analyses, a similar pattern was observed, with one notable exception: the $A P O E$ finding for hippocampus rate of change showing increasing influence of the top SNP with age, was no longer present when correcting for disease. This suggests that the APOE finding for hippocampus was driven by the presence of patients (Supplementary Table S13).

Given that our main analyses included patients and iSECA analyses showed several associations with disease, we repeated iSECA analyses excluding diagnostic groups in each cohort, which did not change the findings (Supplementary Figure S7D).

\section{Discussion}

Here, we present the first GWAS investigating influences of common genetic variants on brain-structural changes in over 10,000 subjects. The longitudinal design of our study combined with the large age range assessed provides a flexible framework to detect age-independent and age-dependent effects of genetic variants on rates of structural brain changes. We discovered novel 
genetic effects that influence inter-individual differences in both development and aging of brain structures. Many of the genes implicated play a crucial role in early, prenatal brain development. We identified these genes in a population aged 4 to 99 , suggesting that the same genetic variants are also crucial for brain-structural changes later in life.

Our findings show genomic overlap with psychiatric and physiological phenotypes that are associated with longitudinal brain-structural changes such as schizophrenia, smoking, cognitive functioning, and body mass index (Hulshoff Pol and Kahn, 2008; Bobb et al., 2014; Schnack et al., 2015; Kim et al., 2018). Additionally, we find the APOE gene, a major risk factor for $A D$ (Wolfe et al., 2019), to influence amygdala and hippocampus rates of change with varying effects across the lifespan, with probably most pronounced effects in those affected with brain disorders. Gene-set findings imply a role for immune-related processes. Several of the identified genetic variants and genes were linked to metabolic phenotypes, and we found genetic overlap with body mass index, suggesting a role for metabolic processes in longitudinal brain changes.

Given the dynamics of brain structural changes during the lifespan, we investigated both age-independent and age-dependent genetic effects. The age-independent effects can be interpreted as neurodevelopmental influences that also impact brain structure at older ages (Fjell et al., 2015; Walhovd et al., 2016), whereas the age-dependent effects can be interpreted as possible changing effects of genes or gene expression during life (Kang et al., 2011). The genome-wide meta-regression approach employed here may enable future GWAS for other phenotypes that change over the human lifespan.

How exactly variation in these genes impacts brain changes in health and disease cannot be answered based on genome-wide association studies. In this, our findings may direct future studies into brain development and aging, and prevention and treatment of brain disorders. For neurodegenerative disorders, for example, identifying genetic variants that influence brain atrophy over time might well be equally or more important than the identification of static genetic differences. In conclusion, our study shows that our genetic architecture is associated with the dynamics of human brain structure throughout life.

\section{Materials and Methods}

\section{Ethical approval and data availability}

All participants gave written informed consent and all participating sites obtained approval from local research ethics committees/institutional review boards. Ethics approval for meta-analyses within the ENIGMA consortium was granted by the QIMR Berghofer Medical Research Institute Human Research Ethics Committee in Australia (approval: P2204). Upon publication, the meta-analytic results will be made available from the ENIGMA consortium webpage http://enigma.ini.usc.edu/research/download-enigma-gwas-results. 


\section{Inclusion criteria}

Cohorts that had longitudinal magnetic resonance imaging (MRI) data of the brain and genotyped data extracted from blood or saliva available were invited to participate, irrespective of disease status and age. Patients were not excluded as aberrant brain trajectories are often observed and we hypothesize that genetic risk for disease may be associated with genetic influences on rates of change. We included cohorts that had a preferred sample size of at least 75 subjects and a follow up duration (for repeated MRI scans) of at least six months. After quality control of individual subject's imaging and genotyping data, not all the cohorts could meet these criteria. In total, we included 10,163 subjects aged 4 to 99 (50\% female, $22 \%$ patients). Please see Supplementary Figure S1 and Supplementary Table S1 for further description of the cohorts.

\section{Longitudinal imaging}

Eight global brain measures (total brain including cerebellum and excluding brainstem, surface area measured at the grey-white matter boundary, average cortical thickness, total lateral ventricle volume, and cortical and cerebellar grey and white matter volume) and seven subcortical structures (thalamus, caudate, putamen, pallidum, hippocampus, amygdala and nucleus accumbens) were extracted from the FreeSurfer processing pipeline (Fischl et al., 2002, 2004; Reuter, Schmansky, Rosas, \& Fischl, 2012; see Supplementary Table S2 for details per cohort). We chose these measures based on the fact that they show generally high test-retest reliability for crosssectional measures e.g. (Iscan et al., 2015; Liem et al., 2015; Wonderlick 2009), thereby selecting those measures that would have sufficient signal to noise in change measures. Image processing and quality control were performed at the level of the cohorts, following harmonized protocols (http://enigma.ini.usc.edu/protocols/imaging-protocols/) which included visual inspection of the segmentation. Annual rates of change were computed in each individual for each phenotype by subtracting baseline brain measures from follow up measures and dividing by the number of years of follow-up duration. We chose not to correct for overall head size in this analysis: while this is common practice for investigating cross-sectional brain volumes (Voevodskaya et al., 2014), the influence of overall head size on brain changes over time is small (Supplementary Figure S2). Distributions of baseline and follow-up measures - as well as annual rates of changes - were visually inspected and change rates were centrally compared for consistency.

Longitudinal trajectories of brain structure rates of change were estimated by applying locally, cohort-size weighted, estimated scatterplot smoothing with a Gaussian kernel, local polynomials of degree 2 and a span of 1 (LOWESS; Cleveland, 1979) implemented in R (R Core Team, 2018). Integrating these trajectories and then fitting these to the baseline values of the phenotypes in the cohorts provides trajectories throughout the lifespan. Trajectories were estimated in the full dataset including patients and by excluding diagnostic groups in each cohort separately. 


\section{Genome-wide association analysis}

At each participating site, genotypes were imputed using the 1000 Genomes project dataset (1000 Genomes Project Consortium, 2015) through the Michigan imputation server (https://imputationserver.sph.umich.edu/ - Das et al., 2016) or the Sanger imputation server (McCarthy et al., 2016) (Supplementary Table S3). Subsequently, each site ran the same multidimensional scaling (MDS) analysis protocol, computing MDS components from the combination of their cohort's data with the HapMap3 population (International HapMap Consortium, 2010). This ensured that all sites corrected for ancestry in a consistent manner. See http://enigma.ini.usc.edu/protocols/genetics-protocols/ for the imputation and MDS analysis protocol. Within each cohort genome-wide association was conducted using an additive model, modelling change rate as a function of the genetic variant plus covariates age, sex, age*sex, age ${ }^{2}$, age ${ }^{2 *}$ sex and ancestry (the first four MDS components). Dummy variables were added where appropriate, e.g., when multiple scanners were used. We re-ran these analyses adding a covariate for disease status if the cohorts contained patients and controls. Most sites used our harmonized GWAS protocol, which used raremetalworker (Feng et al., 2014) for analysis (Supplementary Table S3). Regardless of the study design, a kinship matrix was incorporated in these analyses, accounting for relatedness in family studies, or possible unknown kinship in the other studies.

Given the small sample sizes of the individual cohorts, a stringent cohort level quality control was enforced, to exclude variants with a minor allele frequency (MAF) $<0.05$ or variants with imputation $R^{2}$ / info score < 0.75 . Across cohorts and phenotypes, GWAS summary plots (Manhattan plots and $Q Q$ plots) were visually inspected at the central site. If a given cohort / trait showed deviation from expectations, sites were asked to reanalyze their data, which usually involved removal of outliers in the phenotypic data.

\section{Meta-analysis and Meta-regression}

In the cohorts of European ancestry $(\mathrm{N}=9,604)$ we tested three models aggregating the cohort-level data for each phenotype, using standard-error weighted meta-analysis or meta-regression: Under the assumption that effect sizes of single nucleotide polymorphisms (SNPs) were consistent across the lifespan, where the subscript $C$ denotes a cohort and $\varepsilon$ an error term.

1) Effect_SNPc $\sim b_{0}+\varepsilon c$, under the null hypothesis that $b_{0}=0$.

Given that brain changes throughout life are dependent on age, the effects of a genetic variant on brain change is likely to depend on age too. Within cohorts such an age by SNP effect analysis would not have been feasible since longitudinal cohorts that span the age-range between 4-99 years do not exist. Given the widespread mean age among the cohorts included (Supplementary Table 1 and Supplementary Figure S1), it was possible to 
calculate the age-dependent effects across the life span comparing effects of loci between cohorts, through meta-regression. Meta-regression is a sophisticated tool for addressing heterogeneity between cohorts in metaanalyses when the source of heterogeneity is known (in this case, age) (Baker et al., 2009). We estimated the following model under the assumption that the effects of SNPs may vary in size or direction across the lifespan:

2) Effect_SNPc $\sim b_{0}+b_{1}{ }^{*} a g e c+\varepsilon c$ under the null hypothesis that $b_{1}=0(1$ degree of freedom), and

3) Effect_SNPc $\sim b_{0}+b_{1}{ }^{*} a g e c+b_{2}{ }^{*} a g e c^{2}+\varepsilon c$ under the null hypothesis that $\left(b_{1}=b_{2}=0,2\right.$ degrees of freedom).

SNP data were aligned using METAL (Willer, Li, \& Abecasis, 2010) for all three analyses. The age-independent effect of SNPs (model 1) was computed in METAL. For the age-dependent analyses the aligned data were imported into R (version 3.5.0, R Core Team, 2018) and fixed effects metaregression was performed using the R-package metafor (version 2.0-0, Viechtbauer, 2010). Results were filtered on SNPs that were present for at least $50 \%$ of the cohorts and in at least $50 \%$ of the subjects.

\section{Functional mapping}

Functional mapping was performed using the FUMA platform designed for prioritization, annotation and interpretation of GWAS results (Watanabe, Taskesen, Van Bochoven, \& Posthuma, 2017). As the first step, independent significant SNPs in the individual GWAS meta-analysis summary statistics were identified based on their $p$-value $\left(p<5 \times 10^{-8}\right)$ and independence of each other ( $r 2<0.6$ in the $1000 \mathrm{G}$ phase 3 reference) within a $1 \mathrm{Mb}$ window. Thereafter, lead SNPs were identified from independent significant SNPs, which are independent of each other $(r 2<0.1)$. We used FUMA to annotate lead SNPs in genomic risk loci based on the following functional consequences on genes: eQTL data (GTEx v6 and v7 (Lonsdale et al., 2013)), blood eQTL browser (Westra et al., 2013), BIOS QTL browser (Zhernakova et al., 2017), BRAINEAC (Ramasamy et al., 2014), MuTHER (Grundberg et al., 2012), xQTLServer (Ng et al., 2017), the CommonMind Consortium (Fromer et al., 2016) and 3D chromatin interactions from HI-C experiments of 21 tissues/cell types (Schmitt et al., 2016). Next for eQTL mapping and chromatin interaction mapping, genes were mapped using positional mapping, which is based on a maximum distance between SNPs (default 10kb) and genes. Chromatin interaction mapping was performed with significant chromatin interactions (defined as FDR $<1 \times 10^{-6}$ ). The two ends of significant chromatin interactions were defined as follows: region $1-a$ region overlapping with one of the candidate SNPs, and region 2 - another end of the significant interaction, used to map to genes based on overlap with a promoter region (250bp upstream and 50bp downstream of the transcription start site). 


\section{Visualization of SNP effects}

We visualized the effects of our top SNPs on the lifespan trajectory, assuming no effects of the other SNPs, for easier interpretation of the direction of effect. Similar to the estimation of the lifespan trajectory, we estimated a smoothed version $f(x)$ of the phenotypic change rate using LOWESS (see above) and integrated the rate of change. We added the unknown volume $C$ at the start of our age range by fitting the integrated curve to the baseline data. Suppose $h(x)$ is the unknown rate of change for non-carriers. The additional change rate $g(x)$ for carriers was estimated through the meta-analysis or metaregression. The full dataset contained a fraction $p$ of the carriers of the tested allele. Assuming $p+q=1, f(x)=p^{*}(h(x)+g(x))+q^{*} h(x)=h(x)+p^{*} g(x)$. We created a rate of change curve for non-carriers as $f(x)-p^{*} g(x)$ and a rate of change curve of carriers as $f(x)+q^{*} g(x)$. The offset $C$ is potentially different in carriers and non-carriers, so we estimated this difference by taking the effect of the cross-sectional GWAS data (see below) in this SNP, or a proxy SNP in high linkage disequilibrium (LD).

\section{Gene-based and gene-set analyses}

Gene-based associations with 15 phenotypes were estimated using MAGMA (version 1.07b; de Leeuw et al., 2015) using the summary statistics from ageindependent and age-dependent GWAS meta-analyses of rate of change of global brain measures. Gene names and locations were based on ENSG v92 (Zerbino et al., 2018) as is used in the FUMA pipeline (Watanabe et al., 2017). Association was tested using the SNP-wise mean model, in which the sum of -log(SNP $p$-value) for SNPs located within the transcribed region (defined using NCBI 37.3 gene definitions) was used as the test statistic. LD correction was based on estimates from the 1000 Genomes Project Phase 3 European ancestry samples (1000 Genomes Project Consortium, 2015). To describe the direction of the age effect for significant genes in the agedependent analyses, we subsequently identified the SNPs that were used in the gene-based $p$-value and plotted the age-dependent effect of the top SNP that contributed to the gene-based $p$-value.

The generated gene-based $p$-values were used to analyze sets of genes in order to test for association of genes belonging to specific biological pathways or processes. MAGMA applies a competitive test to analyze if the genes of a gene set are more strongly associated with the trait than other genes, while correcting for a series of confounding effects such as gene length and size of the gene set. For gene sets we used 9,975 sets with $10-$ 1,000 genes from the Gene Ontology sets (Gene Ontology Consortium, 2015) curated from MsigDB 7.0 (Subramanian et al., 2005).

\section{Multiple testing corrections}

We investigated annual rates of change for 15 brain phenotypes, but these are correlated to some extent (Supplementary Figure S2). We therefore estimated the effective number of independent variables based on matrix 
spectral decomposition (Nyholt, 2004) for the largest adolescent cohort (IMAGEN; $\mathrm{N}=1,068$ ) and for the largest elderly cohort (ADNI2; $\mathrm{N}=626$ ). The most conservative estimate of the number of independent traits was 13.93. Despite the fact that models 2 and 3 are nested and therefore not independent, we also corrected for the fact that we performed three analyses per trait. The study-wide significant threshold for the genome was therefore set at $p<1.2 \mathrm{e}-09$ (5e-08/13.93*3). For gene-based significance, we applied a genome-wide significance level of $0.05 / 18,217=2.64 \mathrm{e}-06$, and a study wide significance of $2.64 \mathrm{e}-06 /\left(13.93^{*} 3\right)$, i.e. $p<6.6 \mathrm{e}-08$. For gene-set significance, we applied a genome-wide significance level of $0.05 / 9,975=5.01 \mathrm{e}-06$ and $\mathrm{a}$ study-wide significance level of 5.01e-06/(13.93*3), i.e. $p<1.20 \mathrm{e}-07$.

\section{Post-hoc analyses}

\section{SNP heritability}

SNP heritabilities, $h^{2} S N P$, were estimated by using linkage disequilibrium (LD) score regression (LDSR; Bulik-Sullivan et al., 2015) for the Europeanancestry brain change GWASs to ensure matching of population LD structure. For LDSR, we used precomputed LD scores based on the European-ancestry samples of the 1000 Genomes Project (1000 Genomes Project Consortium, 2015) restricted to HapMap3 SNPs (International HapMap Consortium, 2010). The summary statistics with standard LDSC filtering were regressed onto these scores. SNP heritabilities were estimated based on the slope of the LD score regression, with heritabilities on the observed scale calculated. To ensure sufficient power for the genetic correlations, $\mathrm{rg}_{\mathrm{g}}$ was calculated if the Zscore of the $h^{2}$ SNP for the corresponding GWAS was 4 or higher (BulikSullivan et al., 2015).

\section{Comparison with cross-sectional results}

For the genome-wide significant genes and genes associated with genomewide significant SNPs, we compared our findings with cross-sectional GWAS summary statistics when available. To this end datasets from (Elliott et al., 2018; Hibar et al., 2017; Satizabal et al., 2019; Grasby et al., 2020) were requested/downloaded from (http://enigma.ini.usc.edu/research/downloadenigma-gwas-results/; http://big.stats.ox.ac.uk/download_page). Gene-based association analyses for cross-sectional brain GWAS summary statistics were performed using MAGMA (as described above). Additionally, we compared the overlap in the first 1,000 ranked genes to the expected number of overlapping genes based on chance. False discovery rate correction (Benjamini and Hochberg, 1995) was applied to determine over- or underrepresentation of genes from our longitudinal GWAS to the cross-sectional previously published GWAS. 


\section{Genetic overlap with cross-sectional results and other traits}

To investigate genetic overlap with other traits across the genome we applied an adapted version of iSECA (independent SNP effect concordance analysis; Nyholt, 2014) which examines pleiotropy and concordance of the direction of effects between two phenotypes by comparing expected and observed overlap in sets of SNPs from both phenotypes that are thresholded at different levels. From the results at each threshold, heatmap plots are generated containing binomial tests for pleiotropy and Fisher's exact tests for concordance. An empirical $p$-value for overall pleiotropy and concordance is then generated through permutation testing. Our implementation of iSECA also included a $p$-value for overall discordance, as we expect some phenotypes to negatively influence brain-structural change rates. $P$-values were computed using a two-step approach: we first ran 1,000 permutations. If the $p$-value for pleiotropy was below $0.05 / 15$ we reran the analyses with 10,000 permutations to obtain a more precise $p$-value. Summary statistics of change rates were first filtered on SNPs for which $>95 \%$ of the subjects contributed data to remove the sample size dependency of $p$-values and subsequently clumped $(p=1, \mathrm{~kb}=1000)$ to ensure independence of input SNPs.

We investigated the genetic overlap between brain-structural changes and risk for 20 neuropsychiatric, neurological and somatic disorders, and physical and psychological traits. Summary statistics were downloaded or requested for aggression (Pappa et al., 2016), alcohol dependence (Walters et al., 2018), Alzheimer's disease (Lambert et al., 2013), attentiondeficit/hyperactivity disorder (Demontis et al., 2019), autism (Psychiatric Genomics Consortium, 2017), bipolar disorder (Stahl et al., 2019), body mass index (Yengo et al., 2018), brain age gap (Kauffman et al., 2019), cognitive functioning (Savage et al., 2018), depression (Howard et al., 2019), diabetes type 2 (Scott et al., 2017), ever smoking (Watanabe et al., 2019), focal epilepsy (The International League Against Epilepsy Consortium on Complex Epilepsies, 2018), height (Yengo et al., 2018), inflammatory bowel disease (Liu et al., 2015), insomnia (Jansen et al., 2019), multiple sclerosis (Sawcer et al., 2011), Parkinson's disease (Nalls et al., 2018), rheumatoid arthritis (Okada et al., 2014) and schizophrenia (Psychiatric Genomics Consortium, 2014). These phenotypes were chosen because of known associations with brain structure or function, and availability of summary statistics based on large GWA-studies.

Apart from these, we also 1) included intracranial volume (Adams et al., 2016) to investigate the effect of overall head size and 2) tested the overlap between each structure's longitudinal change measure against its cross-sectional brain structure. Pleiotropy, concordance or discordance was considered significant when the $p$-value was smaller than $0.05 / 15^{\star} 22$ $($ \#change rates * \#phenotypes tested $)=1.6 \mathrm{e}-04$.

\section{Brain gene expression}

GENE2FUNC, a core process of FUMA (Functional Mapping and Annotation of Genome-wide Association Studies; http://fuma.ctglab.nl; Watanabe et al., 
2017), was employed to analyze gene expression patterns. For this, a set of 16 genes was used as input, including all genome-wide significant genes and genes harboring genome-wide significant SNPs (compare Table 1 and 2). Gene expression heatmap was constructed employing GTEx v8 (GTEx Consortium, 2015; 54 tissue types) and BrainSpan RNA-seq data across 29 different ages or 11 different developmental stages (Miller et al., 2014). The average of normalized expression per label (zero means across samples) was displayed on the corresponding heatmaps. Expression values are TPM (Transcripts Per Million) for GTEx v8 and RPKM (Read per Kilobase Million) in the case of BrainSpan data set.

\section{Phenome-wide association studies}

To identify phenotypes associated with the candidate SNPs and genes (defined as genome-wide significant SNPs and the genome-wide significant genes and genes associated with genome-wide significant SNPs), a phenome-wide association study (pheWAS) was done for each SNP and/or gene. PheWAS was performed using public data provided by GWASAtlas (https://atlas.ctglab.nl; Watanabe et al., 2019). To correct for multiple testing, the total number of GWASs $(4,756)$ was considered (including GWASs in which the searched SNP or gene was not tested) and the number of tested SNPs and genes, resulting in a Bonferroni corrected $p$-value threshold of 1.05e-05/19, i.e., $p<5.53 \mathrm{e}-07$.

\section{Sensitivity analyses}

The main analyses include available data from all cohorts with European ancestry $(\mathrm{N}=9,623)$. The four cohorts of non-European and mixed ancestry together consist of 540 subjects, who are predominantly children and adolescents (Supplementary Table S3). The number of subjects, heterogeneity in ancestry and the age-distribution do not allow for separate meta-analysis or meta-regression. We therefore added the cohorts of nonEuropean ancestry to the original datasets and reran analyses $(N=10,163)$. In a second analysis, we excluded the 9 cohorts that had $\mathrm{N}<75$ or mean scanning interval $<0.5$ years (Supplementary Table S2), leaving $\mathrm{N}=9,105$ subjects. The main analyses include data from all subjects combined, without correction for disease. This approach was chosen because many neurological and neuropsychiatric diseases are characterized by aberrant brain changes over time, and genes involved in the disease may also be involved in these brain changes. To check whether our results were confounded by disease, we repeated the main analyses excluding diagnostic groups of each cohort $(\mathrm{N}=7,309)$ and by correcting for disease status. 


\section{Figure legends}

Figure 1: Phenotypic brain changes throughout the lifespan.

Visualization of growth and decline of brain structures throughout the lifespan. The subcortical structures are shown in exploded view (a). Individual change rates are shown for (b) amygdala, (c) caudate, (d) cerebral white matter volume, (e) cerebellum cortex volume, (f) cerebellum white matter volume, (g) cortex volume, (h) cortical thickness, (i) hippocampus, (j) lateral ventricle volume, $(\mathrm{k})$ nucleus accumbens, $(\mathrm{I})$ pallidum, $(\mathrm{m})$ putamen, $(\mathrm{n})$ surface area, (o) thalamus and (p) total brain. Annual rates of change $\Delta$ per cohort. "For each structure, the estimated trajectories with confidence intervals (in green) are displayed in the top row (b-p). The size of the points represents the relative size of the cohorts. Standard errors are displayed in gray. Means and standard deviations are based on raw data - no covariates were included. Only cohorts that satisfy $\mathrm{N}>75$ and mean interval $>0.5$ years are shown. The estimated trajectories of the volumes themselves are displayed in the bottom row, for all subjects (solid line) and for subjects not part of diagnostic groups (dashed line).

\section{Figure 2: Genetic effects on rates of brain changes throughout the}

lifespan. a) genome-wide significant SNPs and genes with effects on brain changes at their respective loci across the human genome; Illustrations of the two significant genome-wide loci with significant associated genes for b) ageindependent effect of GPR139 and rs72772740 on lateral ventricle change and c) age-dependent effect of $\mathrm{DACH} 1$ and rs573983368 on white matter change; both b) and c) are represented by Manhattan plot, locus plot, metaregression plot with the meta-regression curve with 95\% confidence interval in red and effect size of cohorts represented by circle size, and trajectory plot with the estimated trajectories of the volumes themselves for carriers and non-carriers of the top SNP; Illustrations of the three other genome-wide genetic effects with d) age-dependent effect of top SNP of APOE on amygdala change and e) age-dependent effect of the top SNP of APOE on hippocampus change; d) and e) are represented by meta-regression curve and estimated trajectories for carriers and non-carriers of the effect allele.

\section{Figure 3: Overlap with other phenotypes}

$P$-values for pleiotropy between change rates of structural brain measures (rows, indicated by $\Delta$ for change rate) and neuropsychiatric, disease-related and psychological traits (columns left of color legend). $P$-values for pleiotropy between change rates of structural brain measures and head size (total brain volume) and the cross-sectional brain measure are displayed on the right (columns right of color legend). Significant overlap $(p<1.6 \mathrm{e}-04)$ is marked with *. 
Fiaure 1 bioRxiv preprint doi: https://doi.org/10.1101/2020.04.24.031138; this version posted April 27, 2020. The copyright holder for this preprint Figure 1 (which was not certified by peer review) is the author/funder, who has granted bioRxiv a license to display the preprint in perpetuity. It is
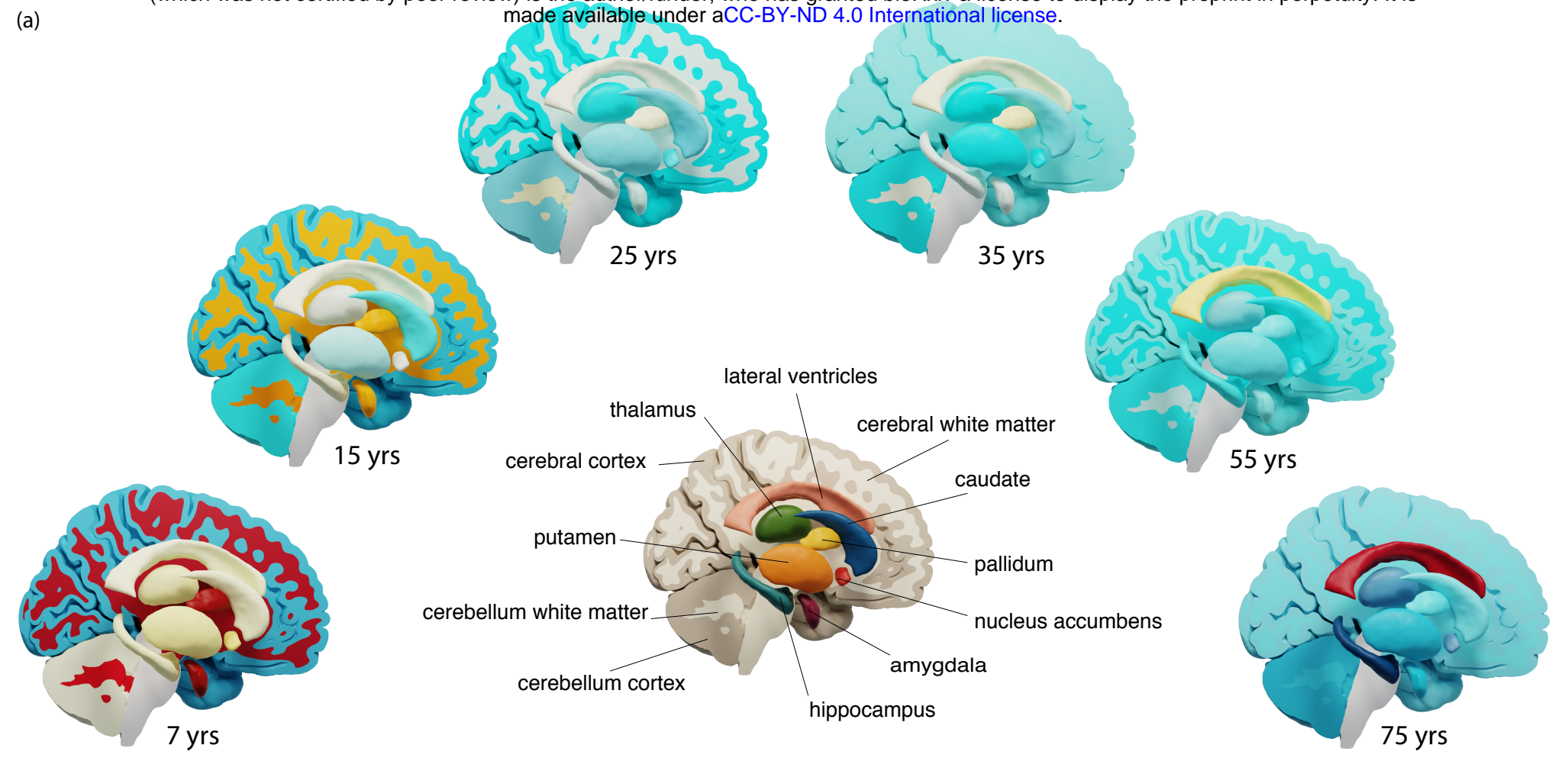

growth

stable

decrease

(b) amygdala

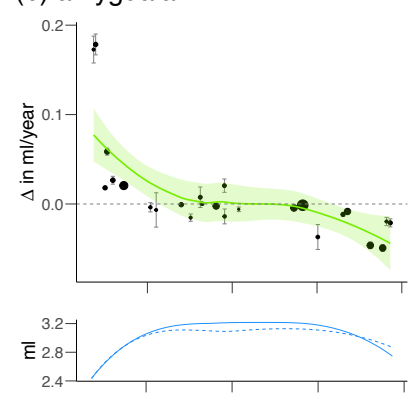

(g) cortex volume

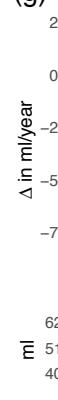

(c) caudate

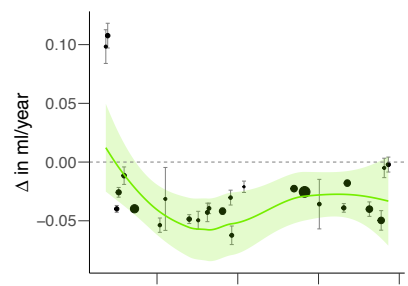

$\bar{\varepsilon} \quad 7.5-$

(h) cortical thickness

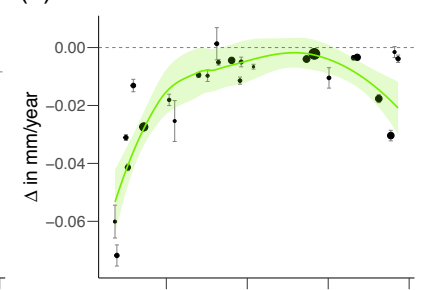

E $\begin{array}{ll}3.0 \\ 2.6\end{array}$

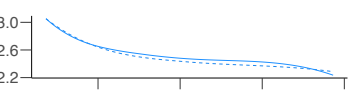

(m) putamen

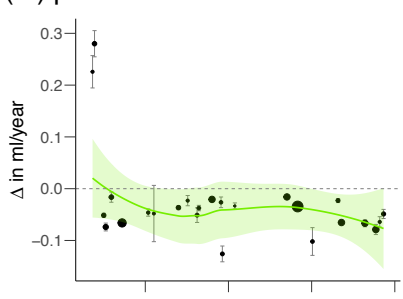

$$
\begin{array}{r}
12.5- \\
\bar{\varepsilon} 11.0- \\
9.5
\end{array}
$$

$\begin{array}{llll}20 & 40 & 60 & 80\end{array}$ age in years age in years (d) cerebral white matter
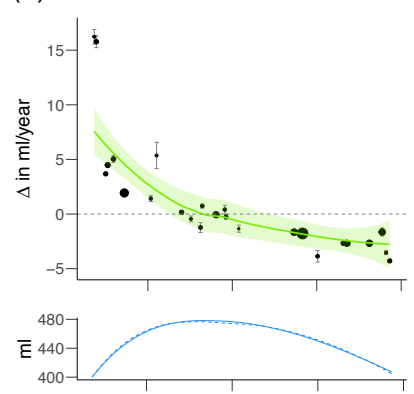

(i) hippocampus

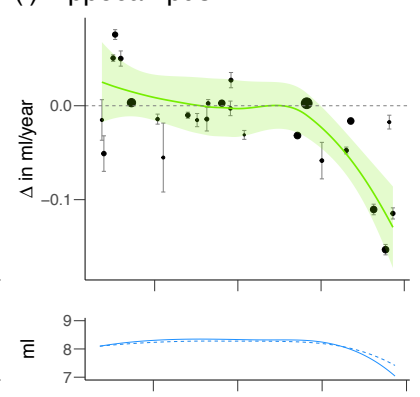

(n) surface area

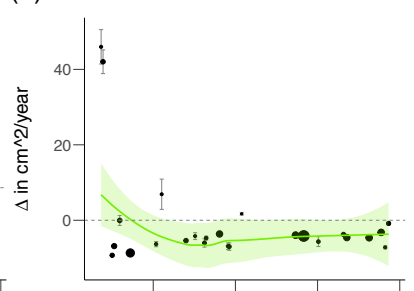

ํํำ 1800

$\begin{array}{llll}20 & 40 \quad 60 \quad 80\end{array}$

$20 \quad 40 \quad 60 \quad 80$ age in years (e) cerebellum cortex

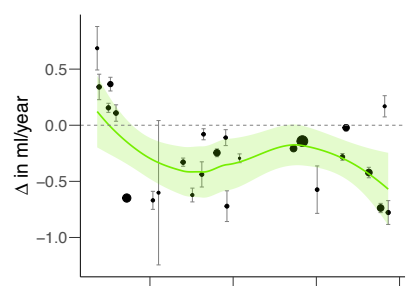

$\bar{\varepsilon} \begin{array}{r}110- \\ 90-\end{array}$

(j) lateral ventricles

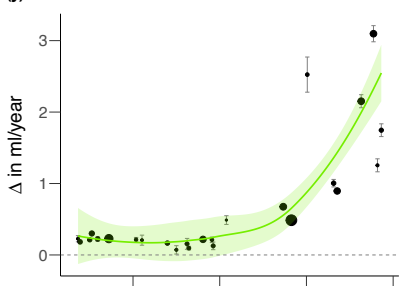

$\bar{\varepsilon}_{30}^{50}-1$

(o) thalamus

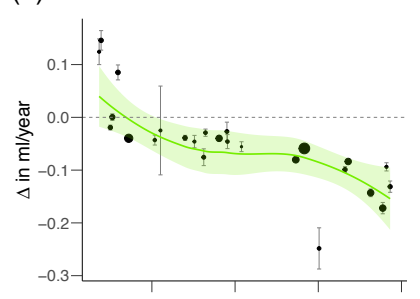

$\bar{\varepsilon}$

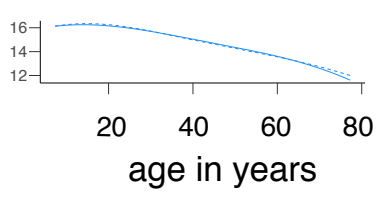

(k) nucleus accumbens

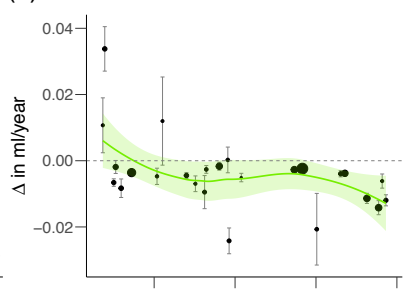

$\bar{\varepsilon} \begin{array}{r}1.30-1 \\ 1.00-\end{array}$

(p) total brain

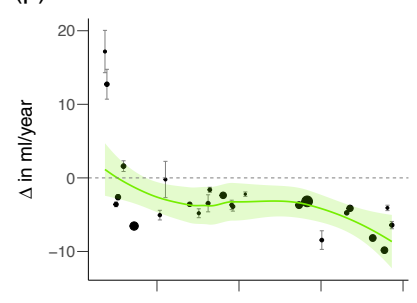

$1200-1$
$\varepsilon_{1000}^{1100}$
$1000-$

um wh

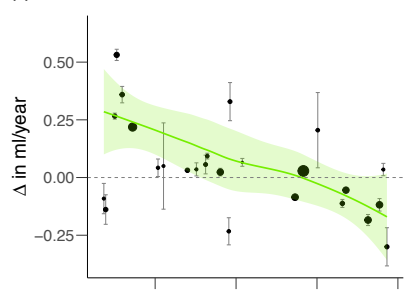

$\bar{\varepsilon} \quad \begin{aligned} & 30- \\ & 25\end{aligned}-$

$20 \quad 40 \quad 60 \quad 80$ age in years 
Figure 2 bioRxiv preprint doi: https://doi.org/10.1101/2020.04.24.031138; this version posted April 27, 2020. The copyright holder for this preprint

(a) (which was not certified by peer review) is the author/funder, who has granted bioRxiv a license to display the preprint in perpetuity. It is
made available under aCC-BY-ND 4.0 International license.

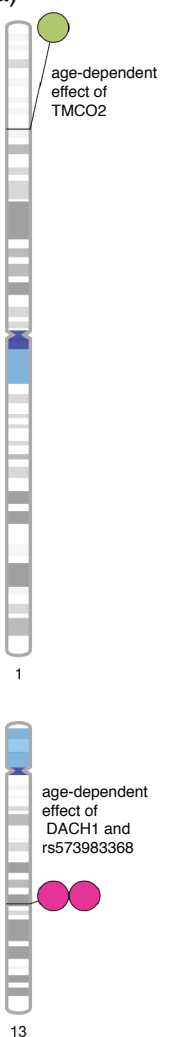

(b)
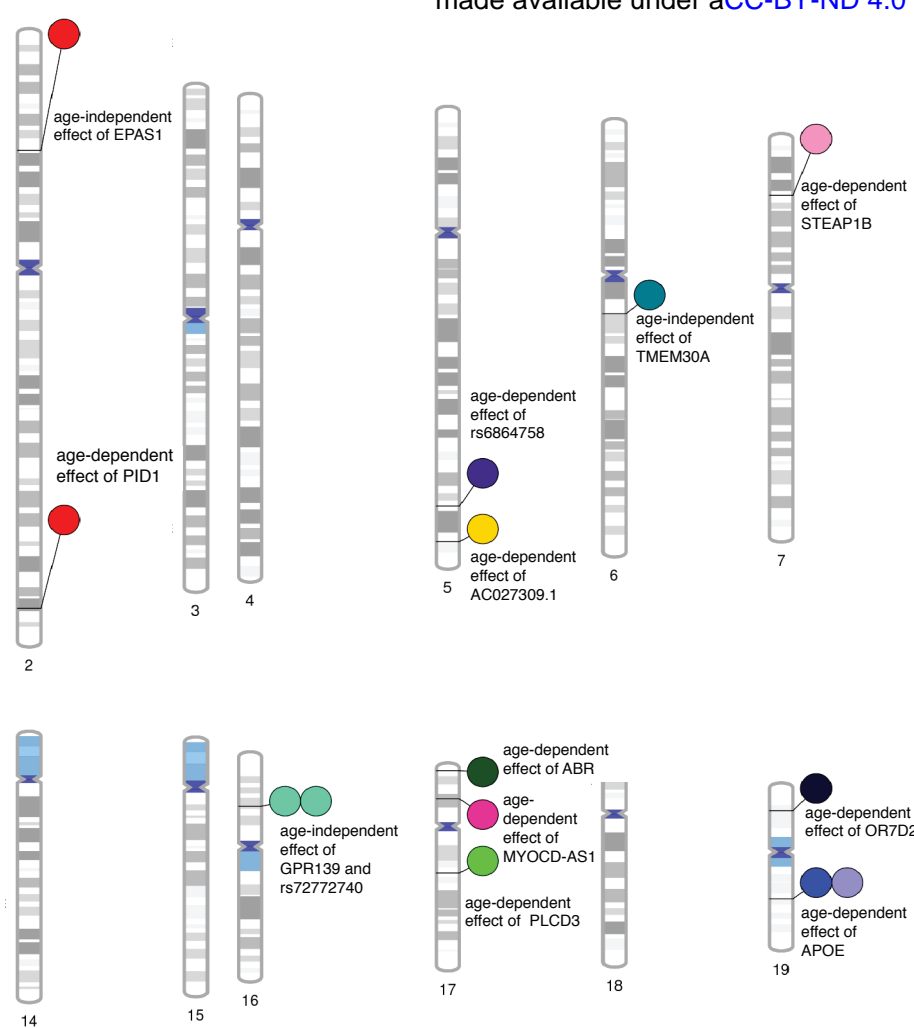

0
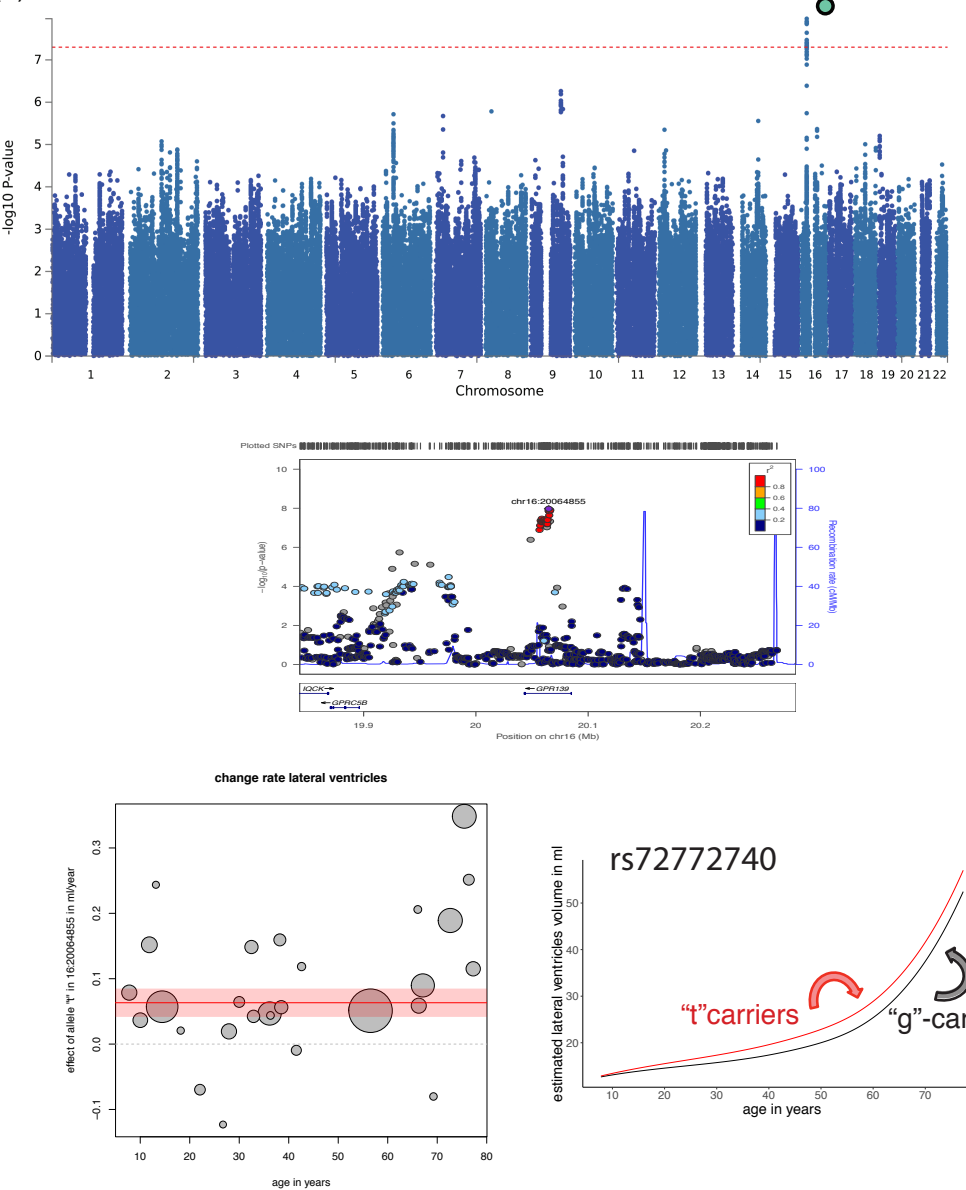

(d)

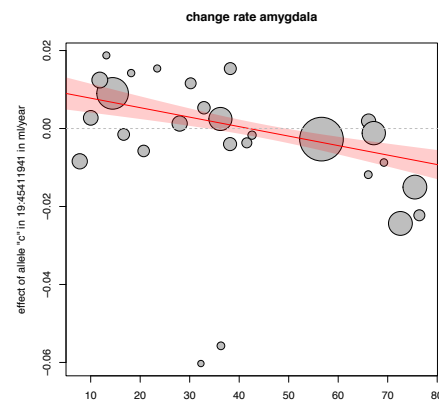

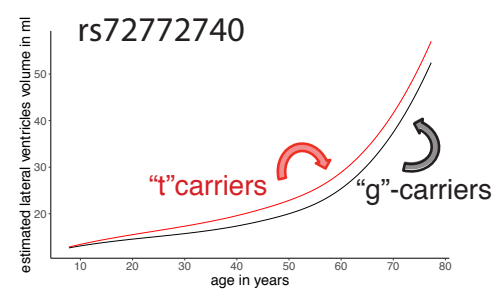
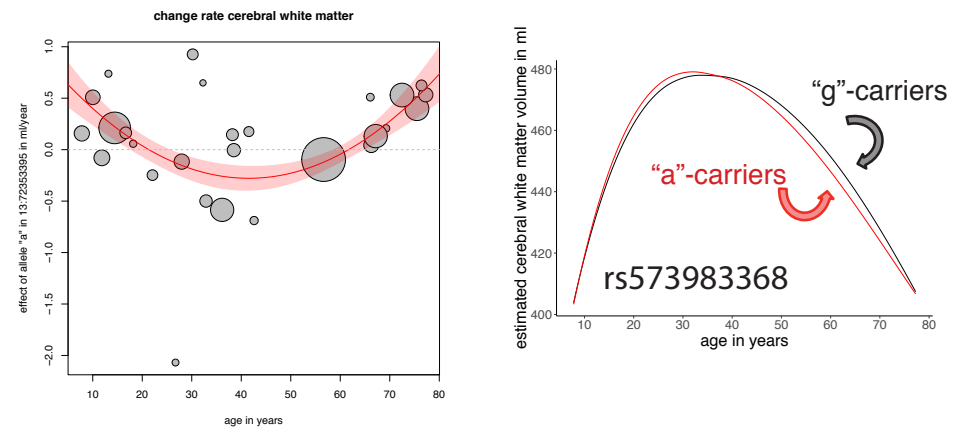

(e)
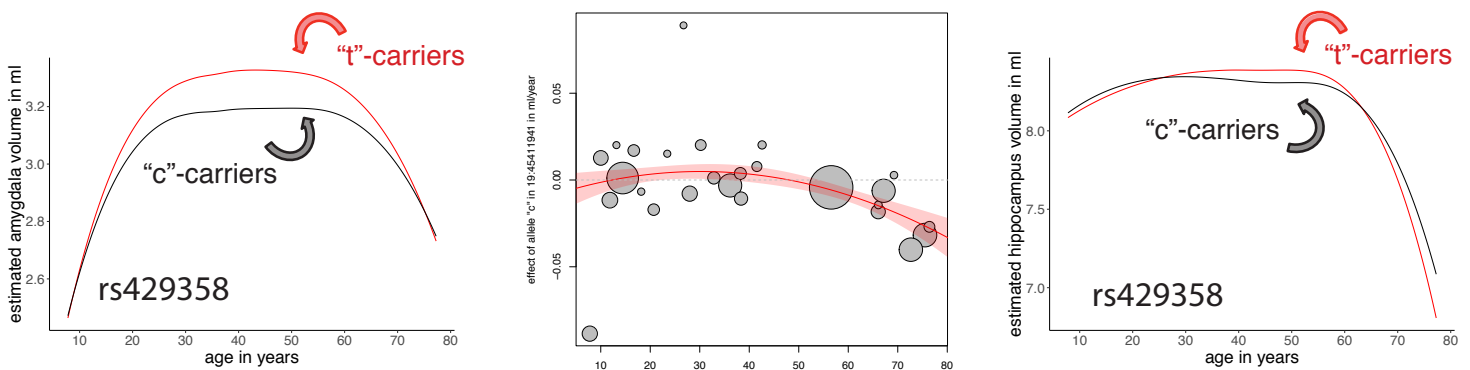

(c)
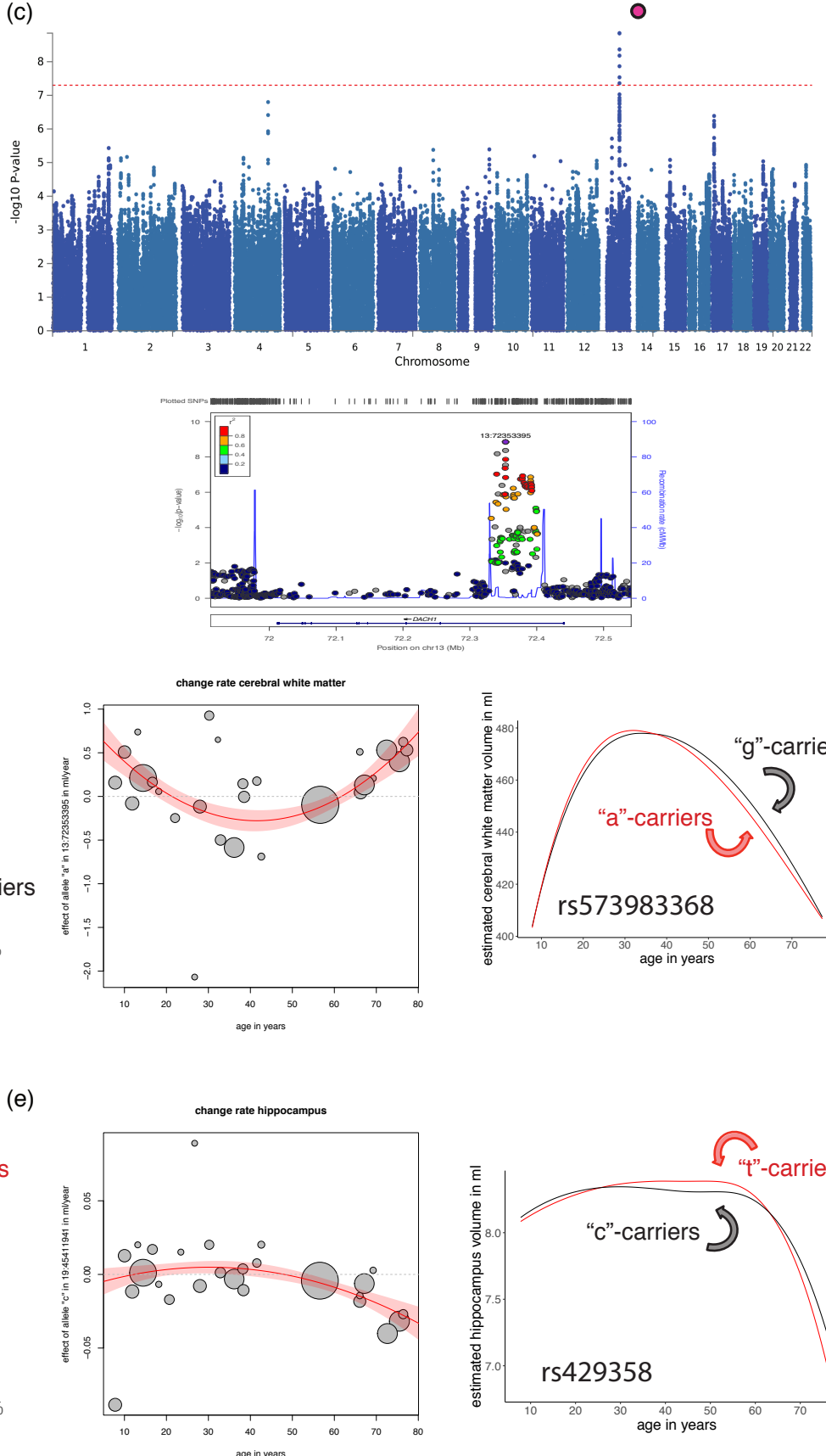


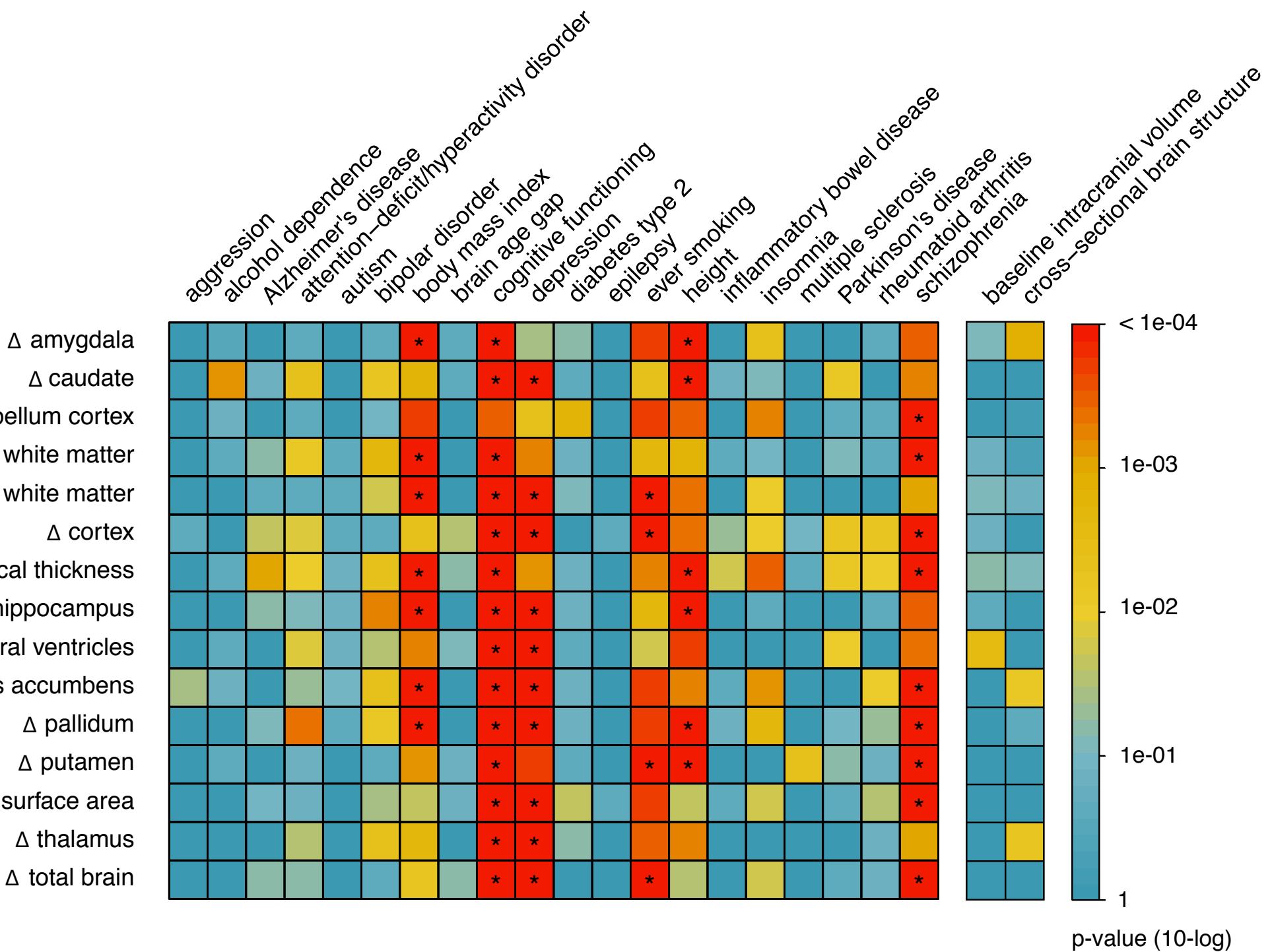

cerebellum white matter

$\Delta$ cerebral white matter

$\Delta$ cortical thickness

$\Delta$ hippocampus

$\Delta$ lateral ventricles

$\Delta$ nucleus accumbens

$\Delta$ pallidum

$\Delta$ putamen

$\Delta$ surface area

$\Delta$ thalamus

$\Delta$ total brain

p-value (10-log) 


\section{Author affiliations}

1. Department of Psychiatry, University Medical Center Utrecht Brain Center, Utrecht University, Utrecht, The Netherlands.

2. Department of Psychiatry, University of California San Diego, La Jolla, CA, USA.

3. Department of Human Genetics, Radboud University Medical Center, Nijmegen, The Netherlands.

4. Donders Institute for Brain, Cognition and Behaviour, Radboud University, Nijmegen, The Netherlands.

5. Psychiatric Genetics, QIMR Berghofer Medical Research Institute, Brisbane, QLD, Australia.

6. Imaging Genetics Center, Mark and Mary Stevens Neuroimaging and Informatics Institute, Keck School of Medicine, University of Southern California, Marina del Rey, CA, USA.

7. Department of Cognitive Neuroscience, Donders Institute for Brain, Cognition and Behaviour, Radboud University Medical Center, Nijmegen, The Netherlands.

8. Department of Psychiatry and Center for Behavior Genetics of Aging, University of California San Diego, La Jolla, CA, USA.

9. American Psychiatric Association, Washington, DC, USA.

10. VA San Diego Center of Excellence for Stress and Mental Health, San Diego, CA, USA.

11. Center for Neurobehavioral Genetics, University of California, Los Angeles, Los Angeles, CA, USA.

12. Biogen Research and Development, Cambridge, MA, USA.

13. Department of Psychiatry, Amsterdam Public Health and Amsterdam Neuroscience, Amsterdam UMC, Vrije Universiteit \& GGZinGeest, Amsterdam, The Netherlands.

14. Department of Child and Adolescent Psychiatry, Institute of Psychiatry and Mental Health, Hospital General Universitario Gregorio Marañón, IiSGM, CIBERSAM, School of Medicine, Universidad Complutense, Madrid, Spain.

15. NORMENT Centre, University of Oslo, Oslo, Norway.

16. Division of Mental Health and Addiction, Oslo University Hospital, Oslo, Norway.

17. INSERM U A10 1000 Trajectoires Développementales en Psychiatrie, Université Paris-Saclay, Ecole Normale Supérieure Paris-Saclay, CNRS, Centre Borelli, Gif-sur-Yvette, France.

18. Valdecilla Biomedical Research Institute (IDIVAL), Marqués de Valdecilla University Hospital (HUMV), School of Medicine, University of Cantabria, Santander, Spain.

19. Department of Neuroimaging, King's College London, London, UK.

20. Department of Child and Adolescent Psychiatry/Psychology, Sophia Children's Hospital, Erasmus University Medical Centre Rotterdam, Rotterdam, The Netherlands.

21. Psychosomatic and CL Psychiatry, Oslo University Hospital, Oslo, Norway.

22. Brain Dynamics Centre, Westmead Institute for Medical Research, The University of Sydney, Westmead, NSW, Australia.

23. Institute of Diagnostic Radiology and Neuroradiology, University Medicine Greifswald, Greifswald, Germany.

24. Centre for Neuroimaging \& Cognitive Genomics (NICOG), Clinical Neuroimaging Laboratory, NCBES Galway Neuroscience Centre, College of Medicine Nursing and Health Sciences, National University of Ireland Galway, Galway, Ireland.

25. Department of Psychosis Studies, Institute of Psychiatry, Psychology and Neuroscience, King's College London, London, UK.

26. Department of Psychiatry, School of Medicine, Pontificia Universidad Católica de Chile, Santiago, Chile.

27. Department of Psychological Medicine, Institute of Psychiatry, Psychology and Neuroscience, King's College London, London, UK.

28. Department of Neurology, Erasmus University Medical Centre Rotterdam, Rotterdam, The Netherlands.

29. Social, Genetic and Developmental Psychiatry Centre, Institute of Psychiatry, Psychology \& Neuroscience, King's College London, London, UK.

30. Department of Psychiatry, University of Münster, Münster, Germany.

31. Section of Systems Neuroscience Department of Psychiatry and Psychotherapy, Technische Universität Dresden, Dresden, Germany.

32. Université Paris-Saclay, CEA, Neurospin, Gif-sur-Yvette, France.

33. University of Groningen, University Medical Center Groningen, Department of Psychiatry, Interdisciplinary Center Psychopathology and Emotion regulation (ICPE), Groningen, The Netherlands.

34. Department of Psychiatry and Mental Health, University of Cape Town, Cape Town, South Africa.

35. Institute of Clinical Radiology, University and University Hospital Münster, Münster, Germany.

36. Departments of Experimental and Clinical Psychology, Vrije Universiteit Amsterdam,

Amsterdam, The Netherlands.

37. Department of Child and Adolescent Psychiatry and Psychotherapy, Central Institute of Mental Health, Medical Faculty Mannheim/Heidelberg University, Mannheim, Germany.

38. Physikalisch-Technische Bundesanstalt (PTB), Berlin, Germany.

39. Department of Clinical Genetics, VUmc, Amsterdam UMC, Amsterdam, The Netherlands. 
bioRxiv preprint doi: https://doi.org/10.1101/2020.04.24.031138; this version posted April 27, 2020. The copyright holder for this preprint (which was not certified by peer review) is the author/funder, who has granted bioRxiv a license to display the preprint in perpetuity. It is made available under aCC-BY-ND 4.0 International license.

40. Centre for Population Neuroscience and Precision Medicine (PONS), Institute of Science and Technology for Brain-Inspired Intelligence and MoE Key Laboratory of Computational Neuroscience and Brain-Inspired Intelligence, Fudan University, Shanghai, China.

41. Centre for Population Neuroscience and Precision Medicine (PONS), Institute of Psychiatry, Psychology and Neuroscience, SGDP Centre, King's College London, London, UK.

42. Centre for Healthy Brain Ageing (CHeBA), School of Psychiatry, University of New South Wales, Kengsington, NSW, Australia.

43. Institute of Neuroscience and Medicine (INM-1), Research Centre Jülich, Jülich, Germany.

44. Department of Psychiatry, Psychotherapy and Psychosomatics, RWTH Aachen University, Medical Faculty, Aachen, Germany, Aachen, Germany.

45. Department of Psychiatry and Psychotherapy, University Hospital LMU, Munich, Germany.

46. Department of Radiology, University Hospital LMU, Munich, Germany.

47. Munich Center for Neurosciences (MCN) - Brain \& Mind, Planegg-Martinsried, Germany.

48. School of Psychiatry, University of New South Wales, Randwick, NSW, Australia.

49. School of Psychiatry and Behavioral Sciences, School of Medicine, University of New Mexico, Albuquerque, NM, USA.

50. Neuroscience Research Australia, Randwick, NSW, Australia.

51. Department of Psychiatry and Psychotherapy, University Medical Center Göttingen, Göttingen, Germany.

52. School of Psychology and Centre for Brain Research, The University of Auckland, Auckland, New Zealand.

53. Brain Research New Zealand, New Zealand.

54. Cécile and Oskar Vogt Institute for Brain Research, Medical Faculty, University Hospital Düsseldorf, Heinrich Heine University Düsseldorf, Düsseldorf, Germany.

55. Department of Biomedicine, University of Basel, Basel, Switzerland.

56. Neuroimaging Unit, Technological Facilities, Valdecilla Biomedical Research Institute IDIVAL, Santander, Spain.

57. APHP, Sorbonne Université, Pitie-Salpetriere Hospital, Department of Child and Adolescent Psychiatry, Paris, France.

58. Department of Mental Health, Institute of Translational Psychiatry, The University of Münster, Münster, Germany.

59. Psychiatric Imaging Group, MRC London Institute of Medical Sciences (LMS), Imperial College London, London, UK.

60. Department of Epidemiology, Erasmus University Medical Centre Rotterdam, Rotterdam, The Netherlands.

61. Department of Radiology \& Nuclear Medicine, Erasmus MC, University Medical Center Rotterdam, Rotterdam, The Netherlands.

62. Department of Psychiatry and Psychotherapy, Philipps-University Marburg, Marburg, Germany.

63. Social and Behavioral Research Branch, National Human Genome Research Institute, Bethesda, MD, USA.

64. Department of Neuropsychiatry, Wakayama Medical University, Wakayama, Japan.

65. CIBERSAM, Biomedical Research Network on Mental Health Area, Santander, Spain.

66. Department of Neurology, University Medical Center Utrecht Brain Center, Utrecht University, Utrecht, The Netherlands.

67. German Center for Neurodegenerative Diseases (DZNE), Site Rostock/Greifswald, Greifswald, Germany.

68. Department of Psychiatry and Psychotherapy, University Medicine Greifswald, Greifswald, Germany.

69. Laboratory of Integrative Neuroscience (LiNC), Department of Psychiatry, Universidade Federal de São Paulo (UNIFESP), São Paulo, SP, Brazil.

70. Mathematics and Statistics, Murdoch University, Murdoch, WA, Australia.

71. Centre for Neuroimaging \& Cognitive Genomics (NICOG), School of Psychology and Discipline of Biochemistry, National University of Ireland Galway, Galway, Ireland.

72. Centre for Human Genetics, Philipps-University Marburg, Marburg, Germany.

73. Institute of Human Genetics, University of Bonn, School of Medicine \& University Hospital Bonn, Bonn, Germany.

74. Interfaculty Institute for Genetics and Functional Genomics, University Medicine Greifswald, Greifswald, Germany.

75. Department of Biological Psychology, Vrije Universiteit Amsterdam, Amsterdam, The Netherlands.

76. Faculty of Medicine and Health, The University of Sydney, Sydney, NSW, Australia.

77. School of Medical Sciences, University of New South Wales, Kensington, NSW, Australia.

78. NORMENT Centre of Excellence, Department of Clinical Science, University of Bergen, Bergen, Norway.

79. Dr. Einar Martens Research Group for Biological Psychiatry, Department of Medical Genetics, Haukeland University Hospital, Bergen, Norway. 
bioRxiv preprint doi: https://doi.org/10.1101/2020.04.24.031138; this version posted April 27, 2020. The copyright holder for this preprint (which was not certified by peer review) is the author/funder, who has granted bioRxiv a license to display the preprint in perpetuity. It is made available under aCC-BY-ND 4.0 International license.

80. Institute of Psychiatric Phenomics and Genomics (IPPG), University Hospital LMU, Munich, Germany.

81. Department of Genetic Epidemiology, Central Institute of Mental Health, Medical Faculty Mannheim, Heidelberg University, Mannheim, Germany.

82. Department of Morphology and Genetics, Universidade Federal de São Paulo (UNIFESP), São Paulo, SP, Brazil.

83. Department of Genetics \& UNC Neuroscience Center, University of North Carolina at Chapel Hill, Chapel Hill, NC, USA.

84. Institute for Community Medicine, University Medicine Greifswald, Greifswald, Germany.

85. School of Mental Health and Neuroscience, Faculty of Health, Medicine and Life Sciences, Maastricht University, Maastricht, The Netherlands.

86. NIHR Maudsley Biomedical Research Centre, South London and Maudsley NHS Trust, London, UK.

87. Department of Psychiatry, Marqués de Valdecilla University Hospital, Valdecilla Biomedical Research Institute (IDIVAL), Santander, Spain.

88. Department of Clinical Genetics,Erasmus University Medical Centre Rotterdam, Rotterdam, The Netherlands.

89. Centre for Psychiatry Research, Department of Clinical Neuroscience, Karolinska Institutet, \& Stockholm Health Care Services, Stockholm County Council, Stockholm, Sweden.

90. Department of Psychiatric Research, Diakonhjemmet Hospital, Oslo, Norway.

91. Academic Unit for Psychiatry of Old Age, University of Melbourne, Parkville, VIC, Australia.

92. National Ageing Research Institute, Parkville, VIC, Australia.

93. Department of Psychiatry, The University of Melbourne, Melbourne, VIC, Australia.

94. Florey Institute of Neuroscience and Mental Health, The University of Melbourne, Melbourne, VIC, Australia.

95. Discipline of Psychiatry and Trinity College Institute of Neuroscience, Trinity College Dublin, Dublin, Ireland.

96. Netherlands Twin Register, Department of Biological Psychology, Vrije Universiteit, Amsterdam, The Netherlands.

97. Instituto Ame Sua Mente, São Paulo, SP, Brazil.

98. Karakter Child and Adolescent Psychiatry University Centre, Nijmegen, The Netherlands.

99. Altrecht Science, Altrecht Mental Health Institute, Utrecht, The Netherlands.

100. Institute for Anatomy I, Medical Faculty, Heinrich Heine University Düsseldorf, Düsseldorf, Germany.

101. Institute of Medical Genetics and Pathology, University Hospital Basel, University of Basel, Basel, Switzerland.

102. Department of Psychiatry, Virgen del Rocio University Hospital, School of Medicine, University of Seville, IBIS, Seville,Spain.

103. NORMENT Centre, Oslo University Hospital, Oslo, Norway.

104. Department of Neurology, Oslo University Hospital, Oslo, Norway.

105. Institute of Clinical Medicine, University of Oslo, Oslo, Norway.

106. Department of Psychology, University of Oslo, Oslo, Norway.

107. Bjørknes College, Oslo, Norway.

108. Language and Genetics Department, Max Planck Institute for Psycholinguistics, Nijmegen, The Netherlands.

109. Department of Cognitive and Clinical Neuroscience, Central Institute of Mental Health, Medical Faculty Mannheim, Heidelberg University, Mannheim, Germany.

110. Department of Psychiatry, University of Vermont, Burlington, VT, USA.

111. Sir Peter Mansfield Imaging Centre, School of Physics and Astronomy, University of Nottingham, Nottingham, UK.

112. Charité Universitätsmedizin Berlin, Berlin, Germany.

113. Department of Child and Adolescent Psychiatry, University of Groningen, Groningen, The Netherlands.

114. Core-Facility Brainimaging, Faculty of Medicine, University of Marburg, Marburg, Germany.

115. Department of Psychiatry, Icahn School of Medicine at Mount Sinai, New York, NY, USA.

116. VISN 2 Mental Illness Research, Education \& Clinical Center (MIRECC) James J. Peters Department of Veterans Affairs Medical Center, Bronx, NY, USA.

117. Department of Psychiatry and Psychotherapy, University of Bonn, Bonn, Germany.

118. Groupe d'Imagerie Neurofonctionnelle, Institut des Maladies Neurodégénératives, CNRS UMR 5293, Université de Bordeaux, Centre Broca Nouvelle-Aquitaine, Bordeaux, France.

119. Unit for Psychosomatic Medicine and C-L Psychiatry, University of Oslo, Oslo, Norway.

120. Black Dog Institute, Sydney, NSW, Australia.

121. Institute of Medical Psychology and Medical Sociology, University Medical Center SchleswigHolstein, Kiel University, Kiel, Germany.

122. Emma Children's Hospital, Amsterdam UMC, University of Amsterdam, Emma Neuroscience Group, department of Pediatrics, Amsterdam Reproduction \& Development, Amsterdam, The Netherlands, Amsterdam, The Netherlands. 
bioRxiv preprint doi: https://doi.org/10.1101/2020.04.24.031138; this version posted April 27, 2020. The copyright holder for this preprint (which was not certified by peer review) is the author/funder, who has granted bioRxiv a license to display the preprint in perpetuity. It is made available under aCC-BY-ND 4.0 International license.

123. Department of Psychiatry, Erasmus Medical Center, Erasmus University, Rotterdam, The Netherlands.

124. National Institute of Developmental Psychiatry for Children and Adolescents (INPD), CNPq, São Paulo, SP, Brazil.

125. Department of Child and Adolescent Psychiatry, University Medical Center Goettingen, Germany, Göttingen, Germany.

126. Neuropsychiatric Institute, The Prince of Wales Hospital, Randwick, NSW, Australia.

127. Department of Psychiatry and Legal Medicine, Universidade Federal do Rio Grande do Sul, Porto Alegre, RS, Brazil.

128. Section on Negative Affect and Social Processes, Hospital de Clínicas de Porto Alegre, Porto Alegre, RS, Brazil.

129. Fudan-KCL PONS Centre, Institute for Science and Technology for Brain-inspired Intelligence (ISTBI), Fudan University, Shanghai, China.

130. PONS Research Group, Department of Psychiatry and Psychotherapy, Charite, Humboldt University, Berlin, Germany.

131. National Institute of Mental Health, National Institutes of Health, Bethesda, MD, USA.

132. West Region, Institute of Mental Health, Singapore.

133. Yong Loo Lin School of Medicine, National University of Singapore, Singapore.

134. Department of Psychiatry and Neuroimaging Center, Technische Universität Dresden, Dresden, Germany.

135. SAMRC Unit on Risk \& Resilience in Mental Disorders, Department of Psychiatry \& Neuroscience Institute, University of Cape Town, Cape Town, South Africa.

136. Department of Developmental Disability Neuropsychiatry, School of Psychiatry, UNSW Sydney, Sydney, NSW, Australia.

137. Charité Universitätsmedizin Berlin, corporate member of Freie Universität Berlin, HumboldtUniversität zu Berlin, and Berlin Institute of Health, Berlin, Germany.

138. Trinity College Institute of Neuroscience, Trinity College Dublin, Dublin, Ireland.

139. Queensland Brain Institute, The University of Queensland, Brisbane, QLD, Australia.

140. Centre for Advanced Imaging, The University of Queensland, Brisbane, QLD, Australia.

141. QIMR Berghofer Medical Research Institute, Brisbane, QLD, Australia.

142. Department of Psychiatry, Radboud University Medical Center, Nijmegen, The Netherlands. Data used in preparing this article were obtained from the Alzheimer's Disease Neuroimaging Initiative (ADNI) database (adni.loni.usc.edu). As such, many investigators within the ADNI contributed to the design and implementation of $\mathrm{ADNI}$ and/or provided data but did not participate in analysis or writing of this report. A complete listing of ADNI investigators may be found at: $\mathrm{http} / / /$ adni.loni.usc.edu/wpcontent/uploads/how to apply/ADNI Acknowledgement List.pdf. A full list of consortium authors can be found below.

\section{Conflicts of interest}

BF has received speaking fees from MEDICE Arzneimittel Pütter GmbH \& Co. BWJHP has received research funding from Jansen Research and Boehringer Ingelheim. CA has been a consultant to or has received honoraria or grants from Acadia, Angelini, Gedeon Richter, Janssen Cilag, Lundbeck, Minerva, Otsuka, Roche, Sage, Servier, Shire, Schering Plough, Sumitomo Dainippon Pharma, Sunovion and Takeda. CDW is an employee of Biogen Inc. DJS has received research grants and/or consultancy honoraria from Lundbeck and Sun. GJB receives honoraria for teaching from GE Healthcare. HB is on the Advisory Board Nutricia Australia. HEH has received travel fees for membership of the Steering Committee of the Lundbeck Foundation Center for Clinical Intervention and Neuropsychiatric Schizophrenia Research and for two presentations from Philips. These concerned activities unrelated to the submitted work. HJG has received travel grants and speaker's honoraria from Fresenius Medical Care, Neuraxpharm, Servier and Janssen Cilag as well as research funding from Fresenius Medical Care. LP has served as an advisor or consultant to Shire, Takeda and Roche. She has received speaking fees from Shire and Infectopharm. The present work is unrelated to these relationships. MHJ received grant support from the Brain and behavior Foundation (NARSAD) Independent Investigator grant number 20244. MMN has received fees for memberships in Scientific Advisory Boards from the Lundbeck Foundation and the Robert-Bosch-Stiftung, and for membership in the Medical-Scientific Editorial Office of the Deutsches Ärzteblatt. MMN was reimbursed travel expenses for a conference participation by Shire Deutschland $\mathrm{GmbH}$. MMN receives salary payments from Life \& Brain $\mathrm{GmbH}$ and holds shares in Life \& Brain $\mathrm{GmbH}$. All these concerned activities outside the submitted work. NJ and PMT are MPI's of a research grant from Biogen, Inc (Boston, USA) for work unrelated to 
the contents of this manuscript. OAA has received Speaker's honorarium from Lundbeck, Consultant for HealthLytix. PSS reports on-off payment for an advisory board meeting of Biogen. TB served in an advisory or consultancy role for Lundbeck, Medice, Neurim Pharmaceuticals, Oberberg $\mathrm{GmbH}$, Shire, and Infectopharm. He received conference support or speaker's fee by Lilly, Medice, and Shire. He received royalties from Hogrefe, Kohlhammer, CIP Medien, Oxford University Press; the present work is unrelated to these relationships. TEI has received speaker's fee from Lundbeck AS. TRM has received honoraria for speaking and chairing engagements from Lundbeck, Janssen and Astellas.

\section{Funding}

The ENIGMA-Plasticity working group is part of the ENIGMA World Aging Center, funded by NIA grant 1R56AG058854-01. The ENIGMA Consortium core funding is supported by NIH Consortium grant U54 EB020403, supported by a cross-NIH alliance that funds Big Data to Knowledge Centers of Excellence.

1000BRAINS: 1000BRAINS is a population-based cohort based on the Heinz-Nixdorf Recall Study and is supported in part by the German National Cohort. We thank the Heinz Nixdorf Foundation (Germany) for their generous support in terms of the Heinz Nixdorf Study. The authors are supported by the Initiative and Networking Fund of the Helmholtz Association (Svenja Caspers) and the European Union's Horizon 2020 Research and Innovation Programme under Grant Agreements 785907 (Human Brain Project SGA2; Svenja Caspers, Sven Cichon, and Katrin Amunts). This work was further supported by the German Federal Ministry of Education and Research (BMBF) through the Integrated Network IntegraMent (Integrated Understanding of Causes and Mechanisms in Mental Disorders) under the auspices of the e:Med Program (grant 01ZX1314A; Sven Cichon), and by the Swiss National Science Foundation (SNSF, grant 156791; Sven Cichon).

ADNI: Data collection and sharing for this project was funded by the Alzheimer's Disease Neuroimaging Initiative (ADNI) (National Institutes of Health Grant U01 AG024904) and DOD ADNI (Department of Defense award number W81XWH-12-2-0012). ADNI is funded by the National Institute on Aging, the National Institute of Biomedical Imaging and Bioengineering, and through generous contributions from the following: AbbVie, Alzheimer's Association; Alzheimer's Drug Discovery Foundation; Araclon Biotech; BioClinica, Inc.; Biogen; BristolMyers Squibb Company; CereSpir, Inc.; Cogstate; Eisai Inc.; Elan Pharmaceuticals, Inc.; Eli Lilly and Company; Eurolmmun; F. Hoffmann-La Roche Ltd and its affiliated company Genentech, Inc.; Fujirebio; GE Healthcare; IXICO Ltd.;Janssen Alzheimer Immunotherapy Research \& Development, LLC.; Johnson \& Johnson Pharmaceutical Research \& Development LLC.; Lumosity; Lundbeck; Merck \& Co., Inc.; Meso Scale Diagnostics, LLC.; NeuroRx Research; Neurotrack Technologies; Novartis Pharmaceuticals Corporation; Pfizer Inc.; Piramal Imaging; Servier; Takeda Pharmaceutical Company; and Transition Therapeutics. The Canadian Institutes of Health Research is providing funds to support ADNI clinical sites in Canada. Private sector contributions are facilitated by the Foundation for the National Institutes of Health (www.fnih.org). The grantee organization is the Northern California Institute for Research and Education, and the study is coordinated by the Alzheimer's Therapeutic Research Institute at the University of Southern California. ADNI data are disseminated by the Laboratory for Neuro Imaging at the University of Southern California.

ALS Utrecht: The authors acknowledge grants supporting their work from the European Union's Horizon 2020 Research and Innovation Programme (H2020/2014-2020) under grant agreements 667302 (CoCA), 728018 (Eat2beNICE), 785907 (HBP SGA2), and 772376 (EScORIAL) and the Netherlands ALS Foundation.

BDC: Brain Dynamics Centre (BDC), Sydney - cohort is funded by a National Health \& Medical Research Council of Australia Project Grant (APP1008080).

BHRCS: The Brazilian High Risk Cohort Study (BHRCS) was supported by the National Institute of Developmental Psychiatry for Children and Adolescent (INPD) Grant: Fapesp 2014/50917-0 CNPq 465550/2014-2. 
BIG: This study used the BIG database, which was established in Nijmegen in 2007. This resource is now part of Cognomics, a joint initiative by researchers of the Donders Centre for Cognitive Neuroimaging, the Human Genetics and Cognitive Neuroscience departments of the Radboud university medical center, and the Max Planck Institute for Psycholinguistics. The Cognomics Initiative is supported by the participating departments and centres and by external grants, including grants from the Biobanking and Biomolecular Resources Research Infrastructure (Netherlands) (BBMRI-NL) and the Hersenstichting Nederland. In particular, the authors would also like to acknowledge grants supporting their work from the Netherlands Organization for Scientific Research (NWO), i.e. the NWO Brain \& Cognition Excellence Program (grant 433-09-229) and the Vici Innovation Program (grant 016-130-669 to BF). Additional support is received from the European Community's Seventh Framework Programme (FP7/2007 - 2013) under grant agreements $n^{\circ} 602805$ (Aggressotype), $n^{\circ}$ 603016 (MATRICS), $n^{\circ} 602450$ (IMAGEMEND), and $n^{\circ} 278948$ (TACTICS), and from the European Community's Horizon 2020 Programme (H2020/2014 - 2020) under grant agreements $n^{\circ} 643051$ (MiND) and $n^{\circ} 667302$ (CoCA).

BrainSCALE: The BrainSCALE study is a collaborative project between Netherland Twin Register (NTR) at the Vrije Universiteit (VU) Amsterdam and University Medical Center Utrecht (UMCU). The BrainSCALE study was funded by Nederlandse Organisatie voor Wetenschappelijk Onderzoek (NWO 51.02.061 to H.H., NWO 51.02.062 to D.B., NWO-NIHC Programs of excellence 433-09- 220 to H.H., NWO-MagW 480-04-004 to D.B., and NWO/SPI 56-464-14192 to D.B.); FP7 Ideas: European Research Council (ERC-230374 to D.B.), Universiteit Utrecht (High Potential Grant to H.H.), Netherlands Twin Registry Repository (NWO-Groot 480-15-001/674 to DB) and Neuroscience Campus Amsterdam (NCA). Biomolecular Resources Research Infrastructure (BBMRI-NL, 184.021.007 and 184.033.111) Developmental trajectories of psychopathology (NIMH 1RC2 MH089995); and the Avera Institute for Human Genetics, Sioux Falls, South Dakota (USA).

Capetown: The CTAAC study was supported by grant No R01-HD074051.

DBSOS: The DBSOS study is partially funded by the Brain and behavior Foundation (NARSAD) by an Independent Investigator grant; No 20244. The generation R Study is made possible by financial support from the Erasmus Medical center, Rotterdam and the Netherlands organization for health research and development (ZonMW). The neuroimaging infrastructure is supported by ZonMW TOP (No: 912110210), The NWO Physical Sciences Division, and SURFsara supercomputing center (Cartesius Compute Cluster).

FOR2107: This work is part of the German multicenter consortium "Neurobiology of Affective Disorders. A translational perspective on brain structure and function", funded by the German Research Foundation (Deutsche Forschungsgemeinschaft DFG;

Forschungsgruppe/Research Unit FOR2107). Grant agreements included the following: FOR2107 DA1151/5-1 and DA1151/5-2 to UD; SFB-TRR58, Projects C09 and Z02 to UD; the Interdisciplinary Center for Clinical Research (IZKF) of the medical faculty of Münster (grant Dan3/012/17 to UD); KR 3822/7-1 and KR 3822/7-2 to AK; KI 588/14-1, KI 588/14-2; NO 246/10-1 and NO 246/10-2 to MMN. AJ was in particular involved as PI in WP6, multi-method data analytics (JA 1890/7-1, JA 1890/7-2). FOR2107 study was also supported by the German Federal Ministry of Education and Research (BMBF), through ERA-NET NEURON, "SynSchiz - Linking synaptic dysfunction to disease mechanisms in schizophrenia - a multilevel investigation" (01EW1810 to MR) and the German Research Foundation (DFG grant FOR2107; RI908/11-2 to MR).

Generation R: Netherlands Organization for Health Research and Development (ZonMw) TOP project number 91211021 . Sophia Children's Hospital Foundation (Stichting Vrienden van het Sophia) project number S18-68. The Generation R sample further reports the following support: Super computing resources for imaging processing were supported by the NWO Physical Sciences Division (Exacte Wetenschappen) and SURFsara (Cartesius compute cluster, https://www.surf.nl); neuroimaging data analysis was supported in part by Sophia Foundation Project S18-20 and Erasmus University Fellowship awarded to RLM. HGUGM: This work was supported by: Spanish Ministry of Science and Innovation, Instituto de Salud Carlos III (SAM16PE07CP1, PI16/02012, PI19/024), co-financed by ERDF Funds from the European Commission, "A way of making Europe", CIBERSAM; Madrid Regional Government (B2017/BMD-3740 AGES-CM-2), European Union Structural Funds; European Union Seventh Framework Program under grant agreements, FP7- HEALTH-2013-2.2.1-2- 
603196 (Project PSYSCAN) and European Union H2020 Program under the Innovative Medicines Initiative 2 Joint Undertaking (grant agreement No 115916, Project PRISM, and grant agreement No 777394, Project AIMS-2-TRIALS), Fundación Familia Alonso, Fundación Alicia Koplowitz and Fundación Mutua Madrileña.

HUBIN: The HUBIN study was funded by: Swedish Research Council (2003-5485, 20062992, 2006-986, 2008-2167, K2012-61X-15078-09-3, 521-2011-4622, 521-2014-3487, 201700949); regional agreement on medical training and clinical research between Stockholm County Council and the Karolinska Institutet; Knut and Alice Wallenberg Foundation.

IMAGEN: This work received support from the following sources: the European Union-funded FP6 Integrated Project IMAGEN (Reinforcement-related behaviour in normal brain function and psychopathology) (LSHM-CT- 2007-037286), the Horizon 2020 funded ERC Advanced Grant 'STRATIFY' (Brain network based stratification of reinforcement-related disorders) (695313), ERANID (Understanding the Interplay between Cultural, Biological and Subjective Factors in Drug Use Pathways) (PR-ST-0416-10004), BRIDGET (JPND: BRain Imaging, cognition Dementia and next generation GEnomics) (MR/N027558/1), Human Brain Project (HBP SGA 2, 785907), the FP7 project MATRICS (603016), the Medical Research Council Grant 'C-VEDA' (Consortium on Vulnerability to Externalizing Disorders and Addictions) (MR/N000390/1), the National Institute for Health Research (NIHR) Biomedical Research Centre at South London and Maudsley NHS Foundation Trust and King's College London, the Bundesministeriumfür Bildung und Forschung (BMBF grants 01GS08152; 01EV0711; Forschungsnetz AERIAL 01EE1406A, 01EE1406B), the Deutsche Forschungsgemeinschaft (DFG grants SM 80/7-2, SFB 940, TRR 265, NE 1383/14-1), the Medical Research Foundation and Medical Research Council (grants MR/R00465X/1 and MR/S020306/1), the National Institutes of Health (NIH) funded ENIGMA (grants 5U54EB020403-05 and 1R56AG058854-01). Further support was provided by grants from: - the ANR (ANR-12SAMA-0004, AAPG2019 - GeBra), the Eranet Neuron (AF12-NEUR0008-01 - WM2NA; and ANR-18-NEUR00002-01 - ADORe), the Fondation de France (00081242), the Fondation pour la Recherche Médicale (DPA20140629802), the Mission Interministérielle de Luttecontre-les-Drogues-et-les-Conduites-Addictives (MILDECA), the Assistance-PubliqueHôpitaux-de-Paris and INSERM (interface grant), Paris Sud University IDEX 2012, the Fondation de l'Avenir (grant AP-RM-17-013), the Fédération pour la Recherche sur le Cerveau; the National Institutes of Health, Science Foundation Ireland (16/ERCD/3797), U.S.A. (Axon, Testosterone and Mental Health during Adolescence; RO1 MH085772-01A1), and by NIH Consortium grant U54 EB020403, supported by a cross-NIH alliance that funds Big Data to Knowledge Centres of Excellence.

NCNG: The NCNG sample collection was supported by grants from the Bergen Research Foundation and the University of Bergen, the Dr Einar Martens Fund, the K.G. Jebsen Foundation, the Research Council of Norway, to SLH, VMS and TE.

NESDA: The infrastructure for the NESDA study (www.nesda.nl) is funded through the Geestkracht program of the Netherlands Organisation for Health Research and Development (ZonMw, grant No 10-000-1002) and financial contributions by participating universities and mental health care organizations (VU University Medical Center, GGZ inGeest, Leiden University Medical Center, Leiden University, GGZ Rivierduinen, University Medical Center Groningen, University of Groningen, Lentis, GGZ Friesland, GGZ Drenthe, Rob Giel Onderzoekscentrum).

NeuroIMAGE: The NeurolMAGE study was supported by NIH Grant R01MH62873 (to Stephen V. Faraone), NWO Large Investment Grant 1750102007010 (to Jan Buitelaar), ZonMW grant 60-60600-97-193, NWO grants 056-13-015 and 433-09-242, and matching grants from Radboud University Nijmegen Medical Center, University Medical Center Groningen and Accare, and Vrije Universiteit Amsterdam. The research leading to these results also received support from the European Community's Seventh Framework Programme (FP7/2007-2013) under grant agreement No 278948 (TACTICS), 602805 (Aggressotype), 603016 (MATRICS) and 602450 (Imagemend), and the Innovation Medicine Initiative grants 115300 (EU-AIMS) and 777394 (AIMS-2-TRIALS).

NUIG: We would like to thank the radiologists at the University Hospital Galway and the participants who generously gave their time to make this study possible. The NUIG sample was supported and funded by the National University of Ireland Galway (NUIG) Millennium Fund and the Health Research Board (HRA_POR/2011/100). 
OATS: We gratefully acknowledge and thank the OATS participants, their supporters and the Research Team. The Older Australian Twin Study (OATS) is supported by the Australian NHMRC/Australian Research Council Strategic Award (Grant 401162) and the NHMRC Project grant 1405325 . This study was facilitated through Twins Research Australia, a national resource in part supported by a Centre for Research Excellence from the NHMRC. DNA was extracted by Genetic Repositories Australia (NHMRC Grant 401184). Genome-wide genotyping at the Diamantina Institute, University of Queensland, was partly funded by a CSIRO Flagship Collaboration Fund Grant.

PAFIP: PAFIP was supported by the Instituto de Salud Carlos III (PI14/00639, PI14/00918 and PI17/01056) and Fundación Instituto de Investigación Marqués de Valdecilla (NCT0235832 and NCT02534363). No pharmaceutical company has financially supported the study.

Rotterdam study: The GWAS datasets are supported by the Netherlands Organization of Scientific Research NWO Investments (nr. 175.010.2005.011, 911-03-012), the Genetic Laboratory of the Department of Internal Medicine, Erasmus MC, the Research Institute for Diseases in the Elderly (014-93-015; RIDE2), the Netherlands Genomics Initiative (NGI)/Netherlands Organization for Scientific Research (NWO) Netherlands Consortium for Healthy Aging (NCHA), project no. 050-060-810. We thank Pascal Arp, Mila Jhamai, Marijn Verkerk, Lizbeth Herrera and Marjolein Peters, MSc, and Carolina Medina-Gomez, MSc, for their help in creating the GWAS database, and Karol Estrada, PhD, Yurii Aulchenko, PhD, and Carolina Medina-Gomez, MSc, for the creation and analysis of imputed data. The Rotterdam Study is funded by Erasmus Medical Center and Erasmus University, Rotterdam, Netherlands Organization for the Health Research and Development (ZonMw), the Research Institute for Diseases in the Elderly (RIDE), the Ministry of Education, Culture and Science, the Ministry for Health, Welfare and Sports, the European Commission (DG XII), and the Municipality of Rotterdam. The authors are grateful to the study participants, the staff from the Rotterdam Study and the participating general practitioners and pharmacists.

SHIP: The SHIP study is part of the Community Medicine Research net of the University of Greifswald, Germany, which is funded by the Federal Ministry of Education and Research (grants no. 01ZZ9603, 01ZZ0103, and 01ZZ0403), the Ministry of Cultural Affairs and the Social Ministry of the Federal State of Mecklenburg-West Pomerania. MRI scans in SHIP and SHIP-TREND have been supported by a joint grant from Siemens Healthineers, Erlangen, Germany and the Federal State of Mecklenburg-West Pomerania.

Sydney MAS: We gratefully acknowledge and thank the Sydney MAS participants, their supporters and the Research Team. The Sydney Memory and Ageing Study (MAS) is supported by a National Health \& Medical Research Council of Australia Program Grant (Grants 350833, 568969, 109308) and a Capacity Building Grant (Grant 568940). DNA samples were extracted by Genetic Repositories Australia, an Enabling Facility, which is supported by a National Health \& Medical Research Council of Australia Grant, 401184. UMCU: The UMCU cohort contains a.o. UTWINS and GROUP. UTWINS was funded by the Netherlands Organization for Health Research and Development ZonMw (908.02.123 and 917.46.370 to H.H.), and by the European Union Marie-Curie Research Training Network (MRTN-CT-2006-035987). The GROUP study is partially funded through the Geestkracht programme of the Dutch Health Research Council (Zon-Mw, grant No 10-0001001), and matching funds from participating pharmaceutical companies (Lundbeck, AstraZeneca, Eli Lilly, Janssen Cilag) and universities and mental health care organizations (Amsterdam: Academic Psychiatric Centre of the Academic Medical Center and the mental health institutions: GGZ Ingeest, Arkin, Dijk en Duin, GGZ Rivierduinen, Erasmus Medical Centre, GGZ Noord Holland Noord. Groningen: University Medical Center Groningen and the mental health institutions: Lentis, GGZ Friesland, GGZ Drenthe, Dimence, Mediant, GGNet Warnsveld, Yulius Dordrecht and Parnassia psycho-medical center The Hague. Maastricht: Maastricht University Medical Centre and the mental health institutions: GGzE, GGZ Breburg, GGZ Oost-Brabant, Vincent van Gogh voor Geestelijke Gezondheid, Mondriaan, Virenze riagg, Zuyderland GGZ, MET ggz, Universitair Centrum Sint-Jozef Kortenberg, CAPRI University of Antwerp, PC Ziekeren Sint-Truiden, PZ Sancta Maria Sint-Truiden, GGZ Overpelt, OPZ Rekem. Utrecht: University Medical Center Utrecht and the mental health institutions Altrecht, GGZ Centraal and Delta.). 
UNSW: The UNSW study was supported by the Australian National Medical and Health Research Council (NHMRC) Program Grant 1037196, Project Grant 1066177, and the Lansdowne Foundation. We gratefully acknowledge the Janette Mary O'Neil Research Fellowship to JMF.

\section{Personal funding}

ALWB received funding from the National Children's Foundation Tallaght, Ireland. CD-C was supported by Instituto de Salud Carlos III, Juan Rodés Grant (JR19/00024). CEF was supported by R01 AG050595; R01 AG022381; P01 AG055367; R01R56 AG037985. DAI was supported by South-Eastern Norway Regional Health Authority (2019107). DJS is supported by the SAMRC. DvdM was supported by Research Council of Norway grant No 276082 . EGJ was supported by Swedish Research Council (2003-5485, 2006-2992, 2006-986, 2008-2167, K2012-61X-15078-09-3, 521-2011-4622, 521-2014-3487, 2017-00949); regional agreement on medical training and clinical research between Stockholm County Council and the Karolinska Institutet; Knut and Alice Wallenberg Foundation; HUBIN project. ESP is supported by Hypatia Tenure Track Grant (Radboudumc); NARSAD Young Investigator Grant (Brain and Behavior Research Foundation ID:25034); Christine Mohrmann Fellowship. EV was supported by National Institute for Health Research (NIHR) Biomedical Research Centre at South London and Maudsley NHS Foundation Trust and King's College London. FN was supported by German Research Foundation NE 1383/14-1. HB was supported by NHMRC Australia. GAS was supported by Conselho Nacional de Desenvolvimento Científico e Tecnológico (CNPq, Brazil; grant No 573974/2008-0), the Coordenação de Aperfeiçoamento de Pessoal de Nível Superior (CAPES, Brazil), the Fundação de Amparo à Pesquisa do Estado de São Paulo (FAPESP, Brazil; grant No 2008/57896-8) and the Fundação de Amparo à Pesquisa do Estado do Rio Grande do Sul (FAPERGS, Brazil). HJG has received research funding from the EU "Joint Programme Neurodegenerative Disorders" (JPND). HHHA was supported by the Netherlands Organization for Health Research and Development (ZonMW, grant No 916.19.151). IAB was supported by University of Sydney Post-graduate Award. IN was supported by DFG Ne2254/1-2. JBJK was supported by NHMRC Dementia Research Team Grant APP1095127. JH was supported by R21MH107327-01. JLS was supported by grant Nos R01MH118349, R01MH120125. KLG was supported by grant No APP1173025. KS was supported by research grants from the National Healthcare Group, Singapore (SIG/05004; SIG/05028; SIG /1103), and the Singapore Bioimaging Consortium (RP C009/2006). LD was supported by R01AG059874 and R01MH117601. JHF was supported by SFB 940/2 and the German Ministry of Education and Research (BMBF Grants 01EV0711 \& 01EE1406B). LHvdB was supported by the Netherlands ALS Foundation. OAA was supported by Research Council of Norway (223273), KG Jebsen Stiftelsen, H2020 CoMorMent (847776). LMOL was supported by K99MH116115. LP received funding from the German Research Foundation (DFG), the Ministry of Science and Education (BMBF) and EU. LTW is funded by the European Research Council under the European Union's Horizon 2020 research and innovation program (ERC Starting Grant 802998), the Research Council of Norway (249795), the South-East Norway Regional Health Authority (2019101), and the Department of Psychology, University of Oslo. MK was supported by funding from the Dutch National Science Agenda NeurolabNL project (grant No 400-17-602). MLPM was supported by the French funding agency ANR (ANR-12-SAMA0004), the Assistance-Publique-Hôpitaux-de-Paris and INSERM (interface grant), ParisDescartes-University (collaborative-project-2010), Paris-Sud-University (IDEX-2012). MLS was supported by FAPESP: 2016/13737-0 and 2016/04983-7. MMN was supported by the German Research Foundation (DFG grant FOR2107; NO246/10-2). MNS was supported by the Deutsche Forschungsgemeinschaft (DFG grants TRR 265; SFB 940; SM 80/7-2) and the German Ministry of Education and Research (BMBF grants 01EV0711; 01EE1406B). MR was supported by DFG FOR2107 RI 908/11-1 \& RI 908/11-2, BMBF Neuron Eranet Synschiz 01EW1810. MSK was supported by the National Health and Medical Research Council, Australia Project Grant (GNT1008080) and Career Development Fellowship (GNT1090148). MSP was supported by NIA R01AG02238.NJ and LD were supported by R01AG059874 and R01MH117601. PMT and SIT were supported by NIH U54 EB020403, R56AG058854 to the ENIGMA World Aging Center, R01MH116147 and P41EB015922. PRS was supported by National Health and Medical Research Council, Australia grant Nos 1037196, 1063960, 
1176716. RA-A is funded by a Miguel Servet contract from the Carlos III Health Institute (CP18/00003), carried out on Fundación Instituto de Investigación Marqués de Valdecilla. PGF received funding from the German Research Foundation, the European Union and the Federeal Ministry of Science. RAB was supported by the European Research Council. SIB was supported by FAPESP 2016/04983-7; FAPESP 2011/50740-5; INCT (CNPq/FAPESP) 2014/50917-0. SEF was supported by the Max Planck Society. SEM was supported by NHMRC APP1103623; APP1172917; APP1158127. SHW was supported by DFG FOR2107 Wi3439/3-2, BMBF Neuron ERANET Synschiz 01EW1810. SLH was supported by the University of Bergen, Trond Mohn Research Foundation, Helse Vest. TEl was funded by the Research Council of Norway, the South-Eastern Norway Regional Health Authority, Oslo University Hospital and a research grant from Mrs. Throne-Holst. TH was supported by grants from the Interdisciplinary Center for Clinical Research (IZKF) of the medical faculty of Münster (grant MzH 3/020/20) and the German Research Foundation (DFG grants HA7070/2-2, HA7070/3, HA7070/4). TJ was supported by National Natural Science Foundation of China (81801773, 81930095, 91630314), the Shanghai Pujiang Project (18PJ1400900), the Key Project of Shanghai Science and Technology Innovation Plan (16JC1420402), the Shanghai Municipal Science and Technology Major Project (No.2018SHZDZX01) and ZHANGJIANG LAB. TRM was supported by Medical Research Council (UK). TW was supported by Netherlands Organization for Health Research and Development (ZonMw) TOP project No 91211021; Sophia Children's Hospital Foundation (Stichting Vrienden van het Sophia) project No S18-68.VM was supported by CONICYT fellowships 21180871. UFM was supported by the Throne-Holst foundation. VMS was supported by Research Council of Norway (grant No 223273 NORMENT). WSK was supported by NIA grants R01 AG050595, R01 AG022381, R01AG060470, R01 AG054002, and NIAAA grant R01 AA026881.

\section{Consortium information and authors}

Data used in the preparation of this article were obtained from the Alzheimer's Disease Neuroimaging Initiative (ADNI) database (adni.loni.usc.edu). The ADNI was launched in 2003 as a public-private partnership, led by Principal Investigator Michael W. Weiner, MD.

ADNI Infrastructure Investigators: Michael Weiner (UC San Francisco), Paul Aisen (University of Southern California), Ronald Petersen (Mayo Clinic, Rochester), Clifford R. Jack, Jr. (Mayo Clinic, Rochester), William Jagust (UC Berkeley), John Q. Trojanowki (U Pennsylvania), Arthur W. Toga (USC), Laurel Beckett (UC), Davis Robert C. Green (Brigham and Women's Hospital/Harvard Medical School), Andrew J. Saykin (Indiana University), John Morris (Washington University St. Louis), Leslie M. Shaw (University of Pennsylvania). ADNI External Advisory Board (ESAB): Zaven Khachaturian (Prevent Alzheimer's Disease 2020 (Chair)), Greg Sorensen (Siemens), Maria Carrillo (Alzheimer's Association), Lew Kuller (University of Pittsburgh), Marc Raichle (Washington University St. Louis), Steven Paul (Cornell University), Peter Davies (Albert Einstein College of Medicine of Yeshiva University), Howard Fillit (AD Drug Discovery Foundation), Franz Hefti (Acumen Pharmaceuticals), David Holtzman (Washington University St. Louis), M. Marcel Mesulam (Northwestern University), William Potter (National Institute of Mental Health), Peter Snyder (Brown University). ADNI 3 Private Partner Scientific Board (PPSB): Veronika Logovinsky, (Eli Lilly (Chair)). Data and Publications Committee: Robert C. Green (BWH/HMS (Chair)). Resource Allocation Review Committee: Tom Montine (University of Washington (Chair)). Clinical Core Leaders: Ronald Petersen (Mayo Clinic, Rochester (Core PI)), Paul Aisen (University of Southern California). Clinical Informatics and Operations: Gustavo Jimenez (USC), Michael Donohue (USC), Devon Gessert (USC), Kelly Harless (USC), Jennifer Salazar (USC), Yuliana Cabrera (USC), Sarah Walter (USC), Lindsey Hergesheimer (USC). Biostatistics Core Leaders and Key Personnel: Laurel Beckett (UC Davis (Core PI)), Danielle Harvey (UC Davis), Michael Donohue (UC San Diego). MRI Core Leaders and Key Personnel: Clifford R. Jack, Jr. (Mayo Clinic, Rochester (Core PI)), Matthew Bernstein (Mayo Clinic, Rochester), Nick Fox (University of London), Paul Thompson (UCLA School of Medicine), Norbert Schuff (UCSF MRI), Charles DeCarli (UC Davis), Bret Borowski (RT Mayo Clinic), Jeff Gunter (Mayo Clinic), Matt Senjem (Mayo Clinic), Prashanthi Vemuri (Mayo Clinic), David Jones (Mayo Clinic), 
Kejal Kantarci (Mayo Clinic), Chad Ward (Mayo Clinic). PET Core Leaders and Key Personnel: William Jagust (UC Berkeley (Core PI)), Robert A. Koeppe (University of Michigan), Norm Foster (University of Utah), Eric M. Reiman (Banner Alzheimer's Institute), Kewei Chen (Banner Alzheimer's Institute), Chet Mathis (University of Pittsburgh), Susan Landau (UC Berkeley). Neuropathology Core Leaders: John C. Morris (Washington University St. Louis), Nigel J. Cairns (Washington University St. Louis), Erin Franklin (Washington University St. Louis), Lisa Taylor-Reinwald (Washington University St. Louis - Past Investigator). Biomarkers Core Leaders and Key Personnel: Leslie M. Shaw (UPenn School of Medicine), John Q. Trojanowki (UPenn School of Medicine), Virginia Lee (UPenn School of Medicine), Magdalena Korecka (UPenn School of Medicine), Michal Figurski (UPenn School of Medicine). Informatics Core Leaders and Key Personnel: Arthur W. Toga (USC (Core PI)), Karen Crawford (USC), Scott Neu (USC). Genetics Core Leaders and Key Personnel: Andrew J. Saykin (Indiana University), Tatiana M. Foroud (Indiana University), Steven Potkin (UC Irvine), Li Shen (Indiana University), Kelley Faber (Indiana University), Sungeun Kim (Indiana University), Kwangsik Nho (Indiana University). Initial Concept Planning \& Development: Michael W. Weiner (UC San Francisco), Leon Thal (UC San Diego), Zaven Khachaturian (Prevent Alzheimer's Disease 2020). Early Project Proposal Development: Leon Thal (UC San Diego), Neil Buckholtz (National Institute on Aging), Michael W. Weiner (UC San Francisco), Peter J. Snyder (Brown University), William Potter (National Institute of Mental Health), Steven Paul (Cornell University), Marilyn Albert (Johns Hopkins University), Richard Frank (Richard Frank Consulting), Zaven Khachaturian (Prevent Alzheimer's Disease 2020). NIA: John Hsiao (National Institute on Aging). ADNI Investigators by Site: Oregon Health \& Science University: Joseph Quinn, Lisa C. Silbert, Betty Lind, Jeffrey A. Kaye - Past Investigator, Raina Carter - Past Investigator, Sara Dolen - Past Investigator. University of Southern California: Lon S. Schneider, Sonia Pawluczyk, Mauricio Becerra, Liberty Teodoro, Bryan M. Spann - Past Investigator. University of California - San Diego: James Brewer, Helen Vanderswag, Adam Fleisher - Past Investigator. University of Michigan: Jaimie Ziolkowski, Judith L. Heidebrink, Joanne L. Lord - Past Investigator. Mayo Clinic, Rochester: Ronald Petersen, Sara S. Mason, Colleen S. Albers, David Knopman, Kris Johnson - Past Investigator. Baylor College of Medicine: Javier Villanueva-Meyer, Valory Pavlik, Nathaniel Pacini, Ashley Lamb, Joseph S. Kass, Rachelle S. Doody - Past Investigator, Victoria Shibley - Past Investigator, Munir Chowdhury - Past Investigator, Susan Rountree - Past Investigator, Mimi Dang - Past Investigator. Columbia University Medical Center: Yaakov Stern, Lawrence S. Honig, Karen L. Bell, Randy Yeh. Washington University, St. Louis: Beau Ances, John C. Morris, David Winkfield, Maria Carroll, Angela Oliver, Mary L. Creech - Past Investigator, Mark A. Mintun - Past Investigator, Stacy Schneider - Past Investigator. University of Alabama - Birmingham: Daniel Marson, David Geldmacher, Marissa Natelson Love, Randall Griffith - Past Investigator, David Clark - Past Investigator, John Brockington Past Investigator. Mount Sinai School of Medicine: Hillel Grossman, Effie Mitsis - Past Investigator. Rush University Medical Center: Raj C. Shah, Melissa Lamar, Patricia Samuels. Wien Center: Ranjan Duara, Maria T. Greig-Custo, Rosemarie Rodriguez. Johns Hopkins University: Marilyn Albert, Chiadi Onyike, Daniel D’Agostino II, Stephanie Kielb - Past Investigator. New York University: Martin Sadowski, Mohammed O. Sheikh, Jamika Singleton-Garvin, Anaztasia Ulysse, Mrunalini Gaikwad. Duke University Medical Center: P. Murali Doraiswamy, Jeffrey R. Petrella, Olga James, Salvador Borges-Neto, Terence Z. Wong - Past Investigator, Edward Coleman - Past Investigator. University of Pennsylvania: Jason H. Karlawish, David A. Wolk, Sanjeev Vaishnavi, Christopher M. Clark - Past Investigator, Steven E. Arnold - Past Investigator. University of Kentucky: Charles D. Smith, Greg Jicha, Peter Hardy, Riham El Khouli, Elizabeth Oates, Gary Conrad. University of Pittsburgh: Oscar L. Lopez, MaryAnn Oakley, Donna M. Simpson. University of Rochester Medical Center: Anton P. Porsteinsson, Kim Martin, Nancy Kowalksi, Melanie Keltz, Bonnie S. Goldstein - Past Investigator, Kelly M. Makino - Past Investigator, M. Saleem Ismail Past Investigator, Connie Brand - Past Investigator. University of California Irvine IMIND: Gaby Thai, Aimee Pierce, Beatriz Yanez, Elizabeth Sosa, Megan Witbracht. University of Texas Southwestern Medical School: Kyle Womack, Dana Mathews, Mary Quiceno. Emory University: Allan I. Levey, James J. Lah, Janet S. Cellar. University of Kansas, Medical Center: Jeffrey M. Burns, Russell H. Swerdlow, William M. Brooks. University of California, Los Angeles: Ellen Woo, Daniel H.S. Silverman, Edmond Teng, Sarah Kremen, Liana 
Apostolova - Past Investigator, Kathleen Tingus - Past Investigator, Po H. Lu - Past Investigator, George Bartzokis - Past Investigator. Mayo Clinic, Jacksonville: Neill R GraffRadford (London), Francine Parfitt, Kim Poki-Walker. Indiana University: Martin R. Farlow, Ann Marie Hake, Brandy R. Matthews - Past Investigator, Jared R. Brosch, Scott Herring. Yale University School of Medicine: Christopher H. van Dyck, Richard E. Carson, Pradeep Varma. McGill Univ., Montreal-Jewish General Hospital: Howard Chertkow, Howard Bergman, Chris Hosein. Sunnybrook Health Sciences, Ontario: Sandra Black, Bojana Stefanovic, Chris (Chinthaka) Heyn. U.B.C. Clinic for AD \& Related Disorders: Ging-Yuek Robin Hsiung, Benita Mudge, Vesna Sossi, Howard Feldman - Past Investigator, Michele Assaly - Past Investigator. Cognitive Neurology - St. Joseph's, Ontario: Elizabeth Finger, Stephen Pasternak, William Pavlosky, Irina Rachinsky - Past Investigator, Dick Drost - Past Investigator, Andrew Kertesz - Past Investigator. Cleveland Clinic Lou Ruvo Center for Brain Health: Charles Bernick, Donna Muni. Northwestern University: Marek-Marsel Mesulam, Emily Rogalski, Kristine Lipowski, Sandra Weintraub, Borna Bonakdarpour, Diana Kerwin Past Investigator, Chuang-Kuo Wu - Past Investigator, Nancy Johnson - Past Investigator. Premiere Research Inst (Palm Beach Neurology): Carl Sadowsky, Teresa Villena. Georgetown University Medical Center: Raymond Scott Turner, Kathleen Johnson, Brigid Reynolds. Brigham and Women's Hospital: Reisa A. Sperling, Keith A. Johnson, Gad A. Marshall. Stanford University: Jerome Yesavage, Joy L. Taylor, Steven Chao, Barton Lane Past Investigator, Allyson Rosen - Past Investigator, Jared Tinklenberg - Past Investigator. Banner Sun Health Research Institute: Edward Zamrini, Christine M. Belden, Sherye A. Sirrel. Boston University: Neil Kowall, Ronald Killiany, Andrew E. Budson, Alexander Norbash Past Investigator, Patricia Lynn Johnson - Past Investigator. Howard University: Thomas $\mathrm{O}$. Obisesan, Ntekim E. Oyonumo, Joanne Allard, Olu Ogunlana. Case Western Reserve University: Alan Lerner, Paula Ogrocki, Curtis Tatsuoka, Parianne Fatica. University of California, Davis - Sacramento: Evan Fletcher, Pauline Maillard, John Olichney, Charles DeCarli, Owen Carmichael - Past Investigator. Neurological Care of CNY: Smita Kittur - Past Investigator. Parkwood Institute: Michael Borrie, T-Y Lee, Dr Rob Bartha. University of Wisconsin: Sterling Johnson, Sanjay Asthana, Cynthia M. Carlsson. Banner Alzheimer's Institute: Pierre Tariot, Anna Burke, Joel Hetelle, Kathryn DeMarco, Nadira Trncic - Past Investigator, Adam Fleisher - Past Investigator, Stephanie Reeder - Past Investigator. Dent Neurologic Institute: Vernice Bates, Horacio Capote, Michelle Rainka. Ohio State University: Douglas W. Scharre, Maria Kataki, Rawan Tarawneh. Albany Medical College: Earl A. Zimmerman, Dzintra Celmins, David Hart. Hartford Hospital, Olin Neuropsychiatry Research Center: Godfrey D. Pearlson, Karen Blank, Karen Anderson. Dartmouth-Hitchcock Medical Center: Laura A. Flashman, Marc Seltzer, Mary L. Hynes, Robert B. Santulli - Past Investigator. Wake Forest University Health Sciences: Kaycee M. Sink, Mia Yang, Akiva Mintz. Rhode Island Hospital: Brian R. Ott, Geoffrey Tremont, Lori A. Daiello. Butler Hospital: Courtney Bodge, Stephen Salloway, Paul Malloy, Stephen Correia, Athena Lee. UC San Francisco: Howard J. Rosen, Bruce L. Miller, David Perry. Medical University South Carolina: Jacobo Mintzer, Kenneth Spicer, David Bachman. St. Joseph's Health Care: Elizabeth Finger, Stephen Pasternak, Irina Rachinsky, John Rogers, Andrew Kertesz - Past Investigator, Dick Drost - Past Investigator. Nathan Kline Institute: Nunzio Pomara, Raymundo Hernando, Antero Sarrael. University of lowa College of Medicine: Delwyn D. Miller, Karen Ekstam Smith, Hristina Koleva, Ki Won Nam, Hyungsub Shim, Susan K. Schultz - Past Investigator. Cornell University: Norman Relkin, Gloria Chiang, Michael Lin, Lisa Ravdin. University of South Florida: USF Health Byrd Alzheimer's Institute: Amanda Smith, Christi Leach, Balebail Ashok Raj - Past Investigator, Kristin Fargher - Past Investigator.

\section{References}

1. The 1000 Genomes Consortium, Auton, A., Abecasis, G. R., Altshuler, D. M., Durbin, R. M., Bentley, D. R., ... Schloss, J. A. (2015). A global reference for human genetic variation. Nature, 526(7571), 68-74. https://doi.org/10.1038/nature15393

2. Adams, H. H., Hibar, D. P., Chouraki, V., Stein, J. L., Nyquist, P. A., Renteria, M. E., ... Thompson, P. M. (2016). Novel genetic loci underlying human intracranial volume identified through genome- 
wide association. Nat Neurosci, 19(12), 1569-1582. https://doi.org/10.1038/nn.4398

3. Agarwala KL, Nakamura S, Tsutsumi Y, Yamakawa K. (2000) Down syndrome cell adhesion molecule DSCAM mediates homophilic intercellular adhesion. Brain research Molecular brain research. 79(1-2):118-126. https://doi.org/10.1016/S0169-328X(00)00108-X

4. Bauer K, Schomburg L, Heuer H, Schafer MK. (1999) Thyrotropin releasing hormone (TRH), the $\mathrm{TRH}$-receptor and the $\mathrm{TRH}$-degrading ectoenzyme; three elements of a peptidergic signalling system. Results and problems in cell differentiation. 26:13-42. https://doi.org/10.1007/978-3-54049421-82.

5. Baker WL, White CM, Cappelleri JC, Kluger J, Coleman Cl, Health Outcomes, Policy, and Economics (HOPE) Collaborative Group (2009). Understanding heterogeneity in meta-analysis: the role of meta-regression. Int J Clin Pract. 2009 Oct;63(10):1426-34. https://doi.org/10.1111/j.17421241.2009.02168.x

6. Benjamini, Y., \& Hochberg, Y. (1995). Journal of the Royal Statistical Society, 57(1), 289-300. https://doi.org/10.1111/j.2517-6161.1995.tb02031.x

7. Bis, J. C., DeCarli, C., Smith, A. V, van der Lijn, F., Crivello, F., Fornage, M., ... Aging Research in Genomic Epidemiology, C. (2012). Common variants at $12 q 14$ and $12 q 24$ are associated with hippocampal volume. Nat Genet, 44(5), 545-551. https://doi.org/10.1038/ng.2237

8. Bobb, J. F., Schwartz, B. S., Davatzikos, C., \& Caffo, B. (2014). Cross-sectional and longitudinal association of body mass index and brain volume. Human Brain Mapping, 35(1), 75-88. https://doi.org/10.1002/hbm.22159

9. Bolkan SS, Stujenske JM, Parnaudeau SP, Spellman TJ, Rauffenbart C, Abbas AI, Harris AZ, Gordon JA, Kellendonk C. (2017). Thalamic projections sustain prefrontal activity during working memory maintenance. Nature Neurosci 20:987-996. https://doi.org/10.1038/nn.4568

10. Brans, R. G., Kahn, R. S., Schnack, H. G., van Baal, G. C., Posthuma, D., van Haren, N. E., ... Hulshoff Pol, H. E. (2010). Brain plasticity and intellectual ability are influenced by shared genes. $J$ Neurosci, 30(16), 5519-5524. https://doi.org/10.1523/JNEUROSCI.5841-09.2010

11. Brans, R. G., van Haren, N. E. M., van Baal, C. G. M., Schnack, H. G., Kahn, R. S., \& Hulshoff Pol, H. E. (2008). Heritability of Changes in Brain Volume Over Time in Twin Pairs Discordant for Schizophrenia. Arch Gen Psychiatry, 65(11), 1259-1268. https://doi.org/10.1001/archpsyc.65.11.1259.

12. Brouwer, R. M., Panizzon, M. S., Glahn, D. C., Hibar, D. P., Hua, X., Jahanshad, N., ... Hulshoff Pol, H. E. (2017). Genetic influences on individual differences in longitudinal changes in global and subcortical brain volumes: Results of the ENIGMA plasticity working group. Hum Brain Mapp, 38(9), 4444-4458. https://doi.org/10.1002/hbm.23672

13. Brouwer, R. M., Hedman, A. M., van Haren, N. E. M., Schnack, H. G., Brans, R. G. H., Smit, D. J. A., ... Hulshoff Pol, H. E. (2014). Heritability of brain volume change and its relation to intelligence. Neurolmage, 100, 676-683. https://doi.org/10.1016/j. neuroimage.2014.04.072

14. Bulik-Sullivan, B. K., Loh, P. R., Finucane, H. K., Ripke, S., Yang, J., Schizophrenia Working Group of the Psychiatric Genomics Consortium, ... Neale, B. M. (2015). LD Score regression distinguishes confounding from polygenicity in genome-wide association studies. Nat Genet, 47(3), 291-295. https://doi.org/10.1038/ng.3211

15. Castellani, C. A., Awamleh, Z., Melka, M. G., Reilly, R. L. O., \& Singh, S. M. (2019). Copy Number Variation Distribution in Six Monozygotic Twin Pairs Discordant for Schizophrenia. 17(2), 108-120. https://doi.org/10.1017/thg.2014.6

16. Cleveland, W.S., Robust Locally Weighted Regression and Smoothing Scatterplots. Journal of the American Statistical Association 74 (368), 829-836. https://doi/org/10.1080/01621459.1979.10481038

17. Crivello, F., Lemaître, H., Dufouil, C., Grassiot, B., Delcroix, N., Tzourio-Mazoyer, N., ... Mazoyer, B. (2010). Effects of ApoE- $\varepsilon 4$ allele load and age on the rates of grey matter and hippocampal volumes loss in a longitudinal cohort of 1186 healthy elderly persons. Neurolmage. https://doi.org/10.1016/j.neuroimage.2009.12.116

18. Das, S., Forer, L., Schönherr, S., Sidore, C., Locke, A. E., Kwong, A., ... Fuchsberger, C. (2016). Next-generation genotype imputation service and methods Sayantan. Nat Genet, 48(10), 12841287. https://doi.org/10.1016/j.physbeh.2017.03.040

19. Demontis, D., Walters, R. K., Martin, J., Mattheisen, M., Als, T. D., Agerbo, E., ... Neale, B. M. (2019). Discovery of the first genome-wide significant risk loci for attention deficit/hyperactivity disorder. Nature Genetics, 51(1), 63-75. https://doi.org/10.1038/s41588-018-0269-7

20. de Leeuw, C. A., Mooij, J. M., Heskes, T., \& Posthuma, D. (2015). MAGMA: Generalized Gene-Set Analysis of GWAS Data. PLoS Computational Biology, 11(4), 1-19. https://doi.org/10.1371/journal.pcbi.1004219

21. Elliott, L. T., Sharp, K., Alfaro-Almagro, F., Shi, S., Miller, K. L., Douaud, G., ... Smith, S. M. (2018). Genome-wide association studies of brain imaging phenotypes in UK Biobank. Nature, 562(7726), 210-216. https://doi.org/10.1038/s41586-018-0571-7

22. Eshaghi, A., Prados, F., Brownlee, W. J., Altmann, D. R., Tur, C., Cardoso, M. J., ... the MAGNIMS 
study group. (2018). Deep gray matter volume loss drives disability worsening in multiple sclerosis. Ann Neurol, 83(2), 210-222. https://doi.org/10.1002/ana.25145.

23. Feng ,S., Liu, D., Zhan, X., Wing, M.K., Abecasis, G.R. (2014) RAREMETAL: fast and powerful meta-analysis for rare variants. Bioinformatics, 30(19), 2828-2829.

https://doi.org/10.1093/bioinformatics/btu367

24. Fischl, B., Salat, D., Busa, E., Albert, M., Dieterich, M., Haselgrove, C., ... Dale, A. M. (2002). Whole Brain Segmentation: Automated Labeling of Neuroanatomical Structures in the Human Brain. Neuron, 33, 341-355. https://doi.org/10.1016/S0896-6273(02)00569-X

25. Fischl, B., Salat, D. H., van der Kouwe, A. J., Makris, N., Segonne, F., Quinn, B. T., \& Dale, A. M. (2004). Sequence-independent segmentation of magnetic resonance images. Neuroimage, 23 Suppl 1, S69-84. https://doi.org/10.1016/j.neuroimage.2004.07.016

26. Fjell, A. M., Grydeland, H., Krogsrud, S. K., Amlien, I., Rohani, D. A., Ferschmann, L., ... Walhovd, K. B. (2015). Development and aging of cortical thickness correspond to genetic organization patterns. Proc Natl Acad Sci U S A. https://doi.org/10.1073/pnas.1508831112

27. Fromer, M., Roussos, P., Sieberts, S. K., Johnson, J. S., Kavanagh, D. H., Perumal, T. M., ... Sklar, P. (2016). Gene expression elucidates functional impact of polygenic risk for schizophrenia. Nature Neuroscience, 19(11), 1442-1453. https://doi.org/10.1038/nn.4399

28. Gene Ontology Consortium (2015). Gene Ontology Consortium : going forward. 43 (November 2014), 1049-1056. https://doi.org/10.1093/nar/gku1179

29. Giedd, J. N., Blumenthal, J. D., Jeffries, N. O., Castellanos, F. X., Liu, H., Zijdenbos, A., ... Rapoport, J. (1999). Brain development during childhood and adolescence: a longitudinal MRI study. Nat Neurosci, 2(10), 861-863. https://doi.org/10.1038/13158.

30. Gogtay, N., Giedd, J. N., Lusk, L., Hayashi, K. M., Greenstein, D., Vaituzis, A. C., ... Thompson, P. M. (2004). Dynamic mapping of human cortical development during childhood through early adulthood. Proc Natl Acad Sci U S A, 101(21), 8174-8179. https://doi.org/10.1073/pnas.040268010

31. Grasby, K.L., Jahanshad, N., Painter, J., Colondro-Conde, L., Bralten, J., Hibar, D.P. Lind, P.A., ... Medland, S.E. (2020). The genetic architecture of the human cerebral cortex. Science, 367 (6484), eaay6690. http://dx. doi.org/10.1101/399402.

32. Grundberg, E., Small, K. S., Hedman, Å. K., Nica, A. C., Buil, A., Keildson, S., ... Spector, T. D. (2012). Mapping cis-and trans-regulatory effects across multiple tissues in twins. Nature Genetics, 44(10), 1084-1089. https://doi.org/10.1038/ng.2394.

33. GTEx Consortium (2015). The Genotype-Tissue Expression (GTEx) pilot analysis: Multitissue gene regulation in humans. Science, 348(6235), 648-660. https://doi.org/10.1126/science.1262110.

34. Hedman, A. M., van Haren, N. E., Schnack, H. G., Kahn, R. S., \& Hulshoff Pol, H. E. (2012). Human brain changes across the life span: a review of 56 longitudinal magnetic resonance imaging studies. Hum Brain Mapp, 33(8), 1987-2002. https://doi.org/10.1002/hbm.21334

35. Hibar, D. P., Adams, H. H., Jahanshad, N., Chauhan, G., Stein, J. L., Hofer, E., ... Ikram, M. A. (2017). Novel genetic loci associated with hippocampal volume. Nat Commun, 8, 13624. https://doi.org/10.1038/ncomms13624

36. Hibar, D. P., Stein, J. L., Renteria, M. E., Arias-Vasquez, A., Desrivieres, S., Jahanshad, N., ... Medland, S. E. (2015). Common genetic variants influence human subcortical brain structures. Nature, 520(7546), 224-229. https://doi.org/10.1038/nature14101

37. Howard, D. M., Adams, M. J., Clarke, T. K., Hafferty, J. D., Gibson, J., Shirali, M., ... Mclntosh, A. M. (2019). Genome-wide meta-analysis of depression identifies 102 independent variants and highlights the importance of the prefrontal brain regions. Nature Neuroscience, 22(3), 343-352. https://doi.org/10.1038/s41593-018-0326-7

38. Hulshoff Pol, H. E., \& Kahn, R. S. (2008). What happens after the first episode? A review of progressive brain changes in chronically ill patients with schizophrenia. Schizophr Bull, 34(2), 354366. https://doi.org/10.1093/schbul/sbm168

39. International HapMap Consortium, Altshuler, D. M., Gibbs, R. A., Peltonen, L., Altshuler, D. M., Gibbs, R. A., ... McEwen, J. E. (2010). Integrating common and rare genetic variation in diverse human populations. Nature, 467(7311), 52-58. https://doi.org/10.1038/nature09298

40. International League Against Epilepsy Consortium on Complex Epilepsies (2018). Genome-wide mega-analysis identifies 16 loci and highlights diverse biological mechanisms in the common epilepsies. Nature Communications, 9(1), 5269. https://doi.org/10.1038/s41467-018-07524-z

41. Iscan, Z., Jin, T. B., Kendrick, A., Szeglin, B., Lu, H., Trivedi, M., ... Delorenzo, C. (2015). Testretest reliability of freesurfer measurements within and between sites: Effects of visual approval process. Human Brain Mapping, Vol. 36, pp. 3472-3485. https://doi.org/10.1002/hbm.22856

42. Jansen, P. R., Watanabe, K., Stringer, S., Skene, N., Bryois, J., Hammerschlag, A. R., ... Posthuma, D. (2019). Genome-wide analysis of insomnia in 1,331,010 individuals identifies new risk loci and functional pathways. Nature Genetics, 51(3), 394-403. https://doi.org/10.1038/s41588018-0333-3

43. Jeppesen, R., \& Benros, M. E. (2019). Autoimmune diseases and psychotic disorders. Frontiers in Psychiatry, 10(MAR), 1-11. https://doi.org/10.3389/fpsyt.2019.00131 
44. Jiskoot LJ, Panman JL, Meeter LH, Dopper EGP, Donker Kaat L, Franzen S, van der Ende EL, van Minkelen R, Rombouts SARB, Papma JM, van Swieten JC. (2019). Longitudinal multi-model MRI as prognostic and diagnostic biomarker in presymptomatic familial frontotemporal dementia. Brain. 142: 193-208. https://doi.org/10.1093/brain/awy288

45. Kang, H., Kawasawa, Y., Cheng, F., Zhu, Y., X, X., Li, M., ... Weinberger, D. R. (2011). Spatiotemporal transcriptome of the human brain. Nature, 478 (7370), 483-489. https://doi.org/10.1038/nature10523

46. Kaufmann, T., Meer, D. Van Der, Doan, N. T., Schwarz, E., Lund, M. J., Agartz, I., ... Westlye, L. T. (2019). Common brain disorders are associated with heritable patterns of apparent aging of the brain. Nature Neuroscience. https://doi.org/10.1038/s41593-019-0471-7

47. Kelly, S., Jahanshad, N., Zalesky, A., Kochunov, P., Agartz, I., Alloza, C., ... Donohoe, G. (2017). Widespread white matter microstructural differences in schizophrenia across 4322 individuals: results from the ENIGMA Schizophrenia DTI Working Group. Mol Psychiatry. https://doi.org/10.1038/mp.2017.170

48. Kim, R. E., Yun, C. H., Thomas, R. J., Oh, J. H., Johnson, H. J., Kim, S., ... Shin, C. (2018). Lifestyle-dependent brain change: a longitudinal cohort MRI study. Neurobiology of Aging. https://doi.org/10.1016/j.neurobiolaging.2018.04.017

49. Lambert, J. C., Ibrahim-Verbaas, C. A., Harold, D., Naj, A. C., Sims, R., Bellenguez, C., ... Seshadri, S. (2013). Meta-analysis of 74,046 individuals identifies 11 new susceptibility loci for Alzheimer's disease. Nature Genetics, 45(12), 1452-1458. https://doi.org/10.1038/ng.2802

50. Liberg, B., Rahm, C., Panayiotou, A., \& Pantelis, C. (2016). Brain change trajectories that differentiate the major psychoses. European J Clin Invest, 46(7), 658-674. https://doi/org/10.1111/eci.12641.

51. Liem, F., Merillat, S., Bezzola, L., Hirsiger, S., Philipp, M., Madhyastha, T., \& Jancke, L. (2015). Reliability and statistical power analysis of cortical and subcortical FreeSurfer metrics in a large sample of healthy elderly. Neuroimage, 108, 95-109. https://doi.org/10.1016/j.neuroimage.2014.12.035

52. Liu, J. Z., Van Sommeren, S., Huang, H., Ng, S. C., Alberts, R., Takahashi, A., ... Weersma, R. K. (2015). Association analyses identify 38 susceptibility loci for inflammatory bowel disease and highlight shared genetic risk across populations. Nature Genetics, 47(9), 979-986. https://doi.org/10.1038/ng.3359

53. Lonsdale, J., Thomas, J., Salvatore, M., Phillips, R., Lo, E., Shad, S., ... Moore, H. F. (2013). The Genotype-Tissue Expression (GTEx) project. Nature Genetics, 45(6), 580-585. https://doi.org/10.1038/ng.2653

54. McCarthy, S., Das, S., Kretzschmar, W., Delaneau, O., Wood, A. R., Teumer, A., ... Marchini, J. (2016). A reference panel of 64,976 haplotypes for genotype imputation. Nature Genetics, $48(10)$, 1279-1283. https://doi.org/10.1038/ng.3643

55. Miller, J. A., Ding, S. L., Sunkin, S. M., Smith, K. A., Ng, L., Szafer, A., ,.. Lein, E. S. (2014). Transcriptional landscape of the prenatal human brain. Nature, 508(7495), 199-206. https://doi.org/10.1038/nature13185

56. Nagy V, Cole T, Van Campenhout C, et al. The evolutionarily conserved transcription factor PRDM12 controls sensory neuron development and pain perception. Cell cycle (Georgetown, Tex). 2015;14(12):1799-1808. https://doi.org/10.1080/15384101.2015.1036209

57. Nalls, M. A., Blauwendraat, C., Vallerga, C.L., Heilbron, K., Bandres-Ciga, S., Chang, D., ..., Singleton, A. B., for the International Parkinson's Disease Genomics Consortium (2018). Expanding Parkinson's disease genetics: novel risk loci, genomic context, causal insights and heritable risk. BioRxiv. http://dx. doi.org/10.1101/388165.

58. Ng, B., White, C. C., Klein, H. U., Sieberts, S. K., McCabe, C., Patrick, E., ... De Jager, P. L. (2017). An xQTL map integrates the genetic architecture of the human brain's transcriptome and epigenome. Nature Neuroscience, 20(10), 1418-1426. https://doi.org/10.1038/nn.4632

59. Nøhr, A. C., Shehata, M. A., Palmer, D., Pokhrel, R., Vallianou, M., Foster, S. R., ... BräunerOsborne, H. (2019). Identification of a novel scaffold for a small molecule GPR139 receptor agonist. Scientific Reports, 9(1), 1-9. https://doi.org/10.1038/s41598-019-40085-9

60. Nyholt, D. R. (2004). A Simple Correction for Multiple Testing for Single-Nucleotide Polymorphisms in Linkage Disequilibrium with Each Other. Am J Hum Genet, 74, 765-769.

61. Okada, Y., Wu, D., Trynka, G., Raj, T., Terao, C., Ikari, K., ... Plenge, R. M. (2014). Genetics of rheumatoid arthritis contributes to biology and drug discovery. Nature, 506(7488), 376-381. https://doi.org/10.1038/nature12873

62. Oschwald, J., Guye, S., Liem, F., Rast, P., Willis, S., Röcke, C., ... Mérillat, S. (2019). Brain structure and cognitive ability in healthy aging: A review on longitudinal correlated change. Reviews in the Neurosciences. https://doi.org/10.1515/revneuro-2018-0096.

63. Pappa, I., St Pourcain, B., Benke, K., Cavadino, A., Hakulinen, C., Nivard, M. G., ... Tiemeier, H. (2016). A genome-wide approach to children's aggressive behavior: The EAGLE consortium. American Journal of Medical Genetics, Part B: Neuropsychiatric Genetics, 171(5), 562-572. 
bioRxiv preprint doi: https://doi.org/10.1101/2020.04.24.031138; this version posted April 27, 2020. The copyright holder for this preprint (which was not certified by peer review) is the author/funder, who has granted bioRxiv a license to display the preprint in perpetuity. It is made available under aCC-BY-ND 4.0 International license.

https://doi.org/10.1002/ajmg.b.32333

64. Piers, R. (2018). Structural brain volume differences between cognitively intact ApoE4 carriers and non-carriers across the lifespan. Neural Regeneration Research, 13(8), 1309-1312.

https://doi.org/10.4103/1673-5374.235408.

65. Pouget, J. G., Han, B., Wu, Y., Mignot, E., Ollila, H. M., Barker, J., ... Knight, J. (2019). Crossdisorder analysis of schizophrenia and 19 immune-mediated diseases identifies shared genetic risk. Human Molecular Genetics, 28(20), 3498-3513. https://doi.org/10.1093/hmg/ddz145

66. Pruim, R. J., Welch, R. P., Sanna, S., Teslovich, T. M., Chines, P. S., Gliedt, T. P., ... Frishman, D. (2011). LocusZoom: Regional visualization of genome-wide association scan results. Bioinformatics, 27(13), 2336-2337. https://doi.org/10.1093/bioinformatics/btq419.

67. Psaty, B. M., Donnell, C. J. O., Gudnason, V., Lunetta, K. L., Folsom, A. R., Rotter, J. I., ... Witteman, J. C. M. (2010). Cohorts for Heart and Aging Research in Genomic Epidemiology (CHARGE) Consortium: Design of prospective meta-analyses of genome-wide association studies from five cohorts. Circ Cardiovasc Genet, 2(1), 73-80.

https://doi.org/10.1161/CIRCGENETICS.108.829747

68. Psychiatric Genomics Consortium (2017). Meta-analysis of GWAS of over 16,000 individuals with autism spectrum disorder highlights a novel locus at 10q24.32 and a significant overlap with schizophrenia. Molecular Autism, 8, 21. https://doi.org/10.1186/s13229-017-0137-9

69. Psychiatric Genomics Consortium (2014). Biological Insights From 108 Schizophrenia-Associated Genetic Loci. Nature, 511(7510), 421-427. https://doi.org/10.1038/nature13595.

70. R Core Team. (2018). R: A language and environment for statistical computing. Retrieved from http://www.r-project.org/

71. Ramsden S, Richardson FM, Josse G, Thomas MSC, Ellis C, Shakeshaft C, Seghier ML, Price CJ. (2011). Verbal and non-verbal intelligence changes in the teenage brain. Nature 479: 113-116. https://doi.org/10.1038/nature10514

72. Rapoport, J. L., \& Gogtay, N. (2008). Brain neuroplasticity in healthy, hyperactive and psychotic children: insights from neuroimaging. Neuropsychopharmacology, 33(1), 181-197. https://doi.org/10.1038/sj.npp. 1301553

73. Raz N, Lindenberger U, Rodrigue KM, Kennedy KM, Head D, Williamson A, Dahle C, Gerstorf D, Acker JD. (2005) Regional brain changes in aging healthy adults: general trends, individual differences and modifiers. Cereb Cortex 15:1676-1689. https://doi.org/10.1093/cercor/bhi044

74. Reiter, K., Nielson, K. A., Durgerian, S., \& Woodard, J. L. (2017). Five-Year Longitudinal Brain Volume Change in Healthy Elders at Genetic Risk for Alzheimer's Disease. 55, 1363-1377. https://doi.org/10.3233/JAD-160504

75. Reuter, M., Schmansky, N. J., Rosas, H. D., \& Fischl, B. (2012). Within-Subject Template Estimation for Unbiased Longitudinal Image Analysis. Neuroimage, 61(4), 14021418.https://doi.org/10.1016/j.neuroimage.2012.02.084

76. Satizabal, C. L., Adams, H. H. H., Hibar, D. P., White, C. C., Knol, M. J., Stein, J. L., ..., Ikram, M.A. (2019). Genetic architecture of subcortical brain structures in 38,851 individuals. 51(November). https://doi.org/10.1038/s41588-019-0511-y

77. Savage, J. E., Jansen, P. R., Stringer, S., Watanabe, K., Bryois, J., De Leeuw, C. A., ... Posthuma, D. (2018). Genome-wide association meta-analysis in 269,867 individuals identifies new genetic and functional links to intelligence. Nature Genetics, 50(7), 912-919. https://doi.org/10.1038/s41588-018-0152-6

78. Ramasamy, A., Trabzuni, D., Guelfi, S., Varghese, V., Smith, C., Walker, R., ... Weale, M. E. (2014). Genetic variability in the regulation of gene expression in ten regions of the human brain. Nature Neuroscience, 17(10), 1418-1428. https://doi.org/10.1038/nn.3801

79. Sawcer, S., Hellenthal, G., Pirinen, M., Spencer, C. C. A., Patsopoulos, N. A., Moutsianas, L., ... Compston, A. (2011). Genetic risk and a primary role for cell-mediated immune mechanisms in multiple sclerosis. Nature, 476(7359), 214-219. https://doi.org/10.1038/nature10251

80. Scott, R. A., Scott, L. J., Mägi, R., Marullo, L., Gaulton, K. J., Kaakinen, M., ... Prokopenko, I. (2017). An Expanded Genome-Wide Association Study of Type 2 Diabetes in Europeans. Diabetes, 66(11), 2888-2902. https://doi.org/10.2337/db16-1253.

81. Schmitt, A. D., Hu, M., Jung, I., Xu, Z., Qiu, Y., Tan, C. L., ... Ren, B. (2016). A Compendium of Chromatin Contact Maps Reveals Spatially Active Regions in the Human Genome. Cell Reports. https://doi.org/10.1016/j.celrep.2016.10.061

82. Schnack, H. G., Van Haren, N. E. M., Brouwer, R. M., Evans, A., Durston, S., Boomsma, D. I., ... Hulshoff Pol, H. E. (2015). Changes in thickness and surface area of the human cortex and their relationship with intelligence. Cerebral Cortex, Vol. 25, pp. 1608-1617. https://doi.org/10.1093/cercor/bht357.

83. Shaw, P., Gogtay, N., \& Rapoport, J. (2010). Childhood psychiatric disorders as anomalies in neurodevelopmental trajectories. Hum Brain Mapp, 31(6), 917-925. https://doi.org/10.1002/hbm.21028

84. Shaw, P., Lalonde, F., Lepage, C., Rabin, C., Eckstrand, K., Sharp, W., ... Rapoport, J. (2009). 
Development of Cortical Asymmetry in Typically Developing Children and Its Disruption in Attention-Deficit/Hyperactivity Disorder. Arch Gen Psychiatry, 66(8), 888-896. https://doi/org/10.1001/archgenpsychiatry.2009.103.

85. Stahl, E. A., Breen, G., Forstner, A. J., McQuillin, A., Ripke, S., Trubetskoy, V., ... Sklar, P. (2019). Genome-wide association study identifies 30 loci associated with bipolar disorder. Nature Genetics, 51(5), 793-803. https://doi.org/10.1038/s41588-019-0397-8

86. Stein, J. L., Medland, S. E., Vasquez, A. A., Hibar, D. P., Senstad, R. E., Winkler, A. M., ... Enhancing Neuro Imaging Genetics through Meta-Analysis, C. (2012). Identification of common variants associated with human hippocampal and intracranial volumes. Nat Genet, 44(5), 552-561. https://doi.org/10.1038/ng.2250

87. Subramanian, A., Tamayo, P., Mootha, V. K., Mukherjee, S., \& Ebert, B. L. (2005). Gene set enrichment analysis: A knowledge-based approach for interpreting genome-wide expression profiles. Proceedings of the National Academy of Sciences of the United States of America, 102(43), 15545-15550. https://doi.org/10.1073/pnas.0506580102

88. Süsens, U., Hermans-Borgmeyer, I., Urny, J., \& Schaller, H. C. (2006). Characterisation and differential expression of two very closely related G-protein-coupled receptors, GPR139 and GPR142, in mouse tissue and during mouse development. Neuropharmacology. https://doi.org/10.1016/j.neuropharm.2005.11.003

89. Thompson, P., Jahanshad, N., R. K. Ching, C., Salminen, L., Thomopoulos, S. I., Bright, J., ... Zelman, V. (2020). ENIGMA and Global Neuroscience: A Decade of Large-Scale Studies of the Brain in Health and Disease across more than 40 Countries. https://doi.org/10.31234/osf.io/qnsh7

90. Thompson, P. M., Stein, J. L., Medland, S. E., Hibar, D. P., Vasquez, A. A., Renteria, M. E., ... Crespo-Facorro, B. (2014). The ENIGMA Consortium: large-scale collaborative analyses of neuroimaging and genetic data. Brain Imaging Behav, 8(2), 153-182. https://doi.org/10.1007/s11682-013-9269-5

91. van der Lee, S. J., Knol, M. J., Chauhan, G., Satizabal, C. L., Smith, A. V., Hofer, E., ... DeCarli, C. (2019). A genome-wide association study identifies genetic loci associated with specific lobar brain volumes. Communications Biology, 2(1), 1-9. https://doi.org/10.1038/s42003-019-0537-9

92. Viechtbauer, W. (2010). Journal of statistical software. Journal of Statistical Software, 36(3), 1-48. https://doi.org/10.1002/wics.10

93. Vojinovic, D., Adams, H. H., Jian, X., Yang, Q., Smith, A. V., Bis, J. C., ... Fornage, M. (2018). Genome-wide association study of 23,500 individuals identifies 7 loci associated with brain ventricular volume. Nature Communications, 9(1), 1-11. https://doi.org/10.1038/s41467-018-06234$\underline{w}$

94. Walhovd, K. B., Krogsrud, S. K., Amlien, I. K., Bartsch, H., Bjørnerud, A., Due-Tønnessen, P., ... Fjell, A. M. (2016). Neurodevelopmental origins of lifespan changes in brain and cognition. Proceedings of the National Academy of Sciences of the United States of America, 113(33), 93579362. https://doi.org/10.1073/pnas.1524259113

95. Walters, R. K., Polimanti, R., Johnson, E. C., McClintick, J. N., Adams, M. J., Adkins, A. E., ... Agrawal, A. (2018). Transancestral GWAS of alcohol dependence reveals common genetic underpinnings with psychiatric disorders. Nature Neuroscience, 21(12), 1656-1669. https://doi.org/10.1038/s41593-018-0275-1

96. Wang, Q., Yang, C., Gelernter, J., \& Zhao, H. (2015). Pervasive pleiotropy between psychiatric disorders and immune disorders revealed by integrative analysis of multiple GWAS. Human Genetics, 134(11-12), 1195-1209. https://doi.org/10.1007/s00439-015-1596-8

97. Watanabe, K., Stringer, S., Frei, O., Mirkov, M. U., Leeuw, C. De, Polderman, T. J. C., ... Posthuma, D. (2019). A global overview of pleiotropy and genetic architecture in complex traits. Nature Genetics, 51(September). https://doi.org/10.1038/s41588-019-0481-0

98. Watanabe, K., Taskesen, E., Van Bochoven, A., \& Posthuma, D. (2017). Functional mapping and annotation of genetic associations with FUMA. Nature Communications, 8(1), 1-10. https://doi.org/10.1038/s41467-017-01261-5.

99. Westra, H. J., Peters, M. J., Esko, T., Yaghootkar, H., Schurmann, C., Kettunen, J., ... Franke, L. (2013). Systematic identification of trans eQTLs as putative drivers of known disease associations. Nature Genetics, 45(10), 1238-1243. https://doi.org/10.1038/ng.2756

100. Willer, C. J., Li, Y., \& Abecasis, G. R. (2010). METAL: fast and efficient meta-analysis of genomewide association scans. Bioinformatics, 26(17), 2190-2191. https://doi.org/10.1093/bioinformatics/btq340

101. Wolfe, C. M., Fitz, N. F., Nam, K. N., Lefterov, I., \& Koldamova, R. (2019). The role of APOE and TREM2 in Alzheimer's disease-Current understanding and perspectives. International Journal of Molecular Sciences, 20(1), 65-70. https://doi.org/10.3390/ijms20010081

102. Wonderlick, J. S., Ziegler, D. A., Hosseini-Varnamkhasti, P., Locascio, J. J., Bakkour, A., van der Kouwe, A., ... Dickerson, B. C. (2009). Reliability of MRI-derived cortical and subcortical morphometric measures: Effects of pulse sequence, voxel geometry, and parallel imaging. Neurolmage. https://doi.org/10.1016/j.neuroimage.2008.10.037 
bioRxiv preprint doi: https://doi.org/10.1101/2020.04.24.031138; this version posted April 27, 2020. The copyright holder for this preprint (which was not certified by peer review) is the author/funder, who has granted bioRxiv a license to display the preprint in perpetuity. It is made available under aCC-BY-ND 4.0 International license.

103. Yamakawa, K., Huo, Y. K., Haendel, M. A., Hubert, R., Chen, X. N., Lyons, G. E., \& Korenberg, J. R. (1998). DSCAM: A novel member of the immunoglobulin superfamily maps in a Down syndrome region and is involved in the development of the nervous system. Human Molecular Genetics, 7(2), 227-237. https://doi.org/10.1093/hmg/7.2.227

104. Yengo, L., Sidorenko, J., Kemper, K. E., Zheng, Z., Wood, A. R., Weedon, M. N., ... Visscher, P. M. (2018). Meta-analysis of genome-wide association studies for height and body mass index in $\sim 700$ 000 individuals of European ancestry. Human Molecular Genetics, 27(20), 3641-3649. https://doi.org/10.1093/hmg/ddy271

105.Zerbino, D. R., Achuthan, P., Akanni, W., Amode, M. R., Barrell, D., Bhai, J., ... Flicek, P. (2018). Ensembl 2018. Nucleic Acids Research, 46(D1), D754-D761. https://doi.org/10.1093/nar/gkx1098 106.Zhernakova, D. V., Deelen, P., Vermaat, M., Van Iterson, M., Van Galen, M., Arindrarto, W., ... Franke, L. (2017). Identification of context-dependent expression quantitative trait loci in whole blood. Nature Genetics, 49(1), 139-145. https://doi.org/10.1038/ng.3737. 